\title{
FY21 AFC Burst Activities with Coated Zircaloy-4 Under Accident Conditions
}

\section{Nuclear Technology \\ Research and Development}

Prepared for

U.S. Department of Energy Nuclear Technology R\&D Program Advanced Fuels Campaign

Approved for public release. Distribution is unlimited.

Authors:

Ben Garrison, Kory Linton, Kenneth Kane, Sam Bell, C. Shane Hawkins, Brandon Johnston, Tim Graening, Andrew T. Nelson Oak Ridge National Laboratory

July 2021 M2FT-21OR020204071 


\title{
DOCUMENT AVAILABILITY
}

Reports produced after January 1, 1996, are generally available free via US Department of Energy (DOE) SciTech Connect.

Website www.osti.gov

Reports produced before January 1, 1996, may be purchased by members of the public from the following source:

\author{
National Technical Information Service \\ 5285 Port Royal Road \\ Springfield, VA 22161 \\ Telephone 703-605-6000 (1-800-553-6847) \\ TDD 703-487-4639 \\ Fax 703-605-6900 \\ E-mail info@ntis.gov \\ Website http://classic.ntis.gov/
}

Reports are available to DOE employees, DOE contractors, Energy Technology Data Exchange representatives, and International Nuclear Information System representatives from the following source:

Office of Scientific and Technical Information

PO Box 62

Oak Ridge, TN 37831

Telephone 865-576-8401

Fax 865-576-5728

E-mail reports@osti.gov

Website https://www.osti.gov/

This report was prepared as an account of work sponsored by an agency of the United States Government. Neither the United States Government nor any agency thereof, nor any of their employees, makes any warranty, express or implied, or assumes any legal liability or responsibility for the accuracy, completeness, or usefulness of any information, apparatus, product, or process disclosed, or represents that its use would not infringe privately owned rights. Reference herein to any specific commercial product, process, or service by trade name, trademark, manufacturer, or otherwise, does not necessarily constitute or imply its endorsement, recommendation, or favoring by the United States Government or any agency thereof. The views and opinions of authors expressed herein do not necessarily state or reflect those of the United States Government or any agency thereof. 
Nuclear Energy and Fuel Cycle Division

\title{
FY21 AFC BURST ACTIVITIES WITH COATED ZIRCALOY-4 UNDER ACCIDENT CONDITIONS
}

\author{
Ben Garrison \\ Kory Linton \\ Ken Kane \\ Sam Bell \\ C. Shane Hawkins \\ Brandon Johnston \\ Tim Graening \\ Andrew T. Nelson
}

July 2021

Prepared for U.S. Department of Energy

Nuclear Technology R\&D Advanced Fuels Campaign

\author{
Prepared by \\ OAK RIDGE NATIONAL LABORATORY \\ Oak Ridge, TN 37831-6283 \\ managed by \\ UT-BATTELLE LLC \\ for the \\ US DEPARTMENT OF ENERGY \\ under contract DE-AC05-00OR22725
}





\section{CONTENTS}

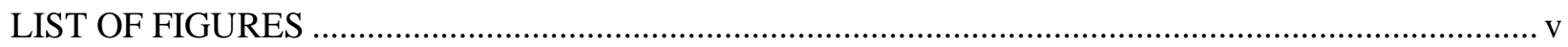

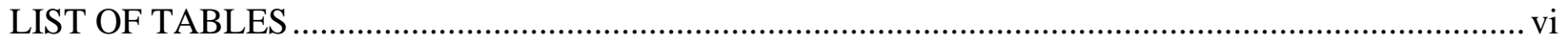

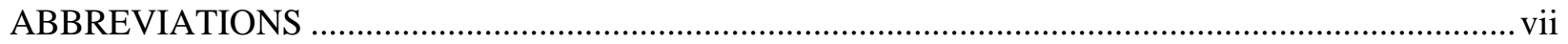

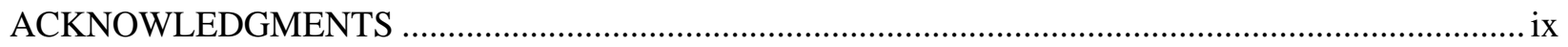

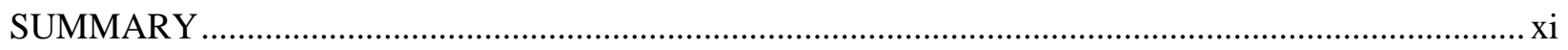

FY21 AFC BURST ACTIVITIES WITH COATED ZIRCALOY-4 UNDER ACCIDENT

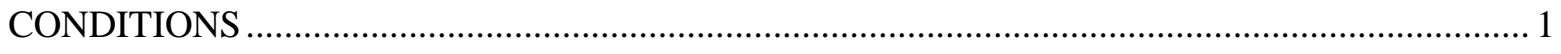

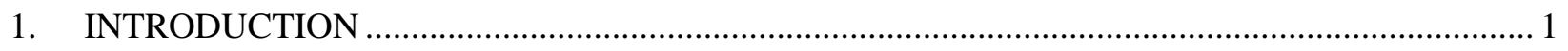

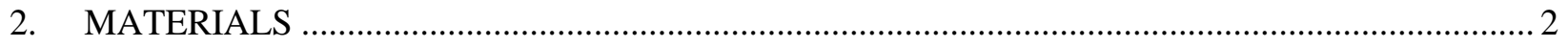

2.1 ZIRCALOY-4 CLADDING MATERIAL ................................................................ 2

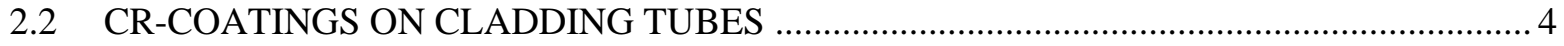

3. SEVERE ACCIDENT TEST STATION .........................................................................

3.1 BURST TESTING EXPERIMENTAL DESIGN ....................................................... 7

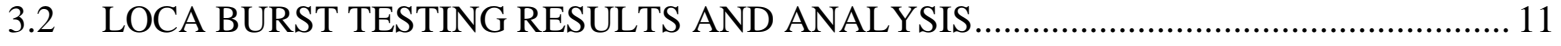

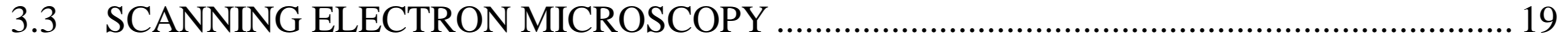

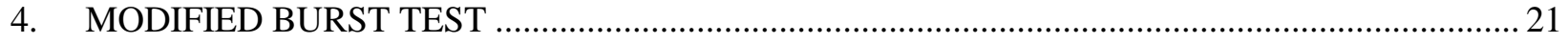

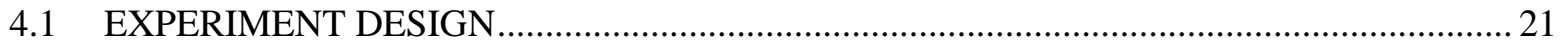

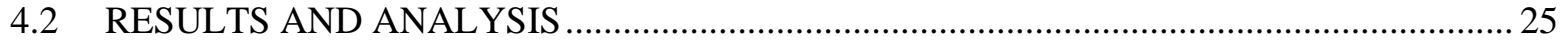

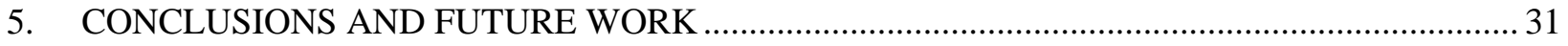

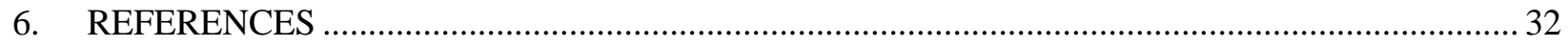





\section{LIST OF FIGURES}

Figure 2-1. Macro- and microscopic images of the surface of Zry-4 tubes in as-received condition.

Figure 2-2. Surface roughness of the three locations of the tube ...................................................... 4

Figure 2-3. As-received and $\mathrm{Cr}$-coated tubes for comparison. ........................................................ 5

Figure 2-4. Cr-coated Zry-4 cladding tubes cut in radial direction, as observed using SEM. ................... 6

Figure 2-5. Cr-coated Zry-4 cladding tubes cut in axial direction, as observed using SEM. ..................... 6

Figure 3-1. Integral LOCA furnace with primary components indicated............................................. 8

Figure 3-2. Test chamber situated inside the IR furnace during LOCA experiment with

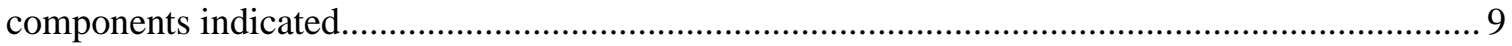

Figure 3-3. Cladding train assembly situated inside test chamber...................................................... 10

Figure 3-4. (a) Temperature and pressure profiles during LOCA burst testing of Zry-4 cladding coated with $\mathrm{Cr}$ at an approximate initial overpressure of $8.3 \mathrm{Mpa}$; (b) close-up of data showing where burst pressure and temperature are taken..................................................... 11

Figure 3-5. Relationship between burst temperature vs. (a) hoop stress and (b) burst pressure................. 13

Figure 3-6. Optical macrographs of burst (top row) Zr4 and (bottom row) $\mathrm{Cr} / \mathrm{Zr} 4$ cladding................... 14

Figure 3-8. Relationship between (a) burst opening length, (b) burst opening width, (c) burst opening area and burst hoop stress for bare Zry-4 and Cr/Zr4 ............................................... 17

Figure 3-9. Diametrical strain of $\mathrm{Zr} 4$ and $\mathrm{Cr} / \mathrm{Zr} 4$ along the cladding length after burst testing................ 18

Figure 3-10. Total strain of claddings' bursts, post-calculated by integrating diametrical strain along cladding length.

Figure 3-11. SEM images of the (a) uncoated Zry-4 180 degrees of circumferential rotation away from the burst near a thermocouple and (b) $\mathrm{Cr} / \mathrm{Zr} 4$ material at 135 degrees of circumferential rotation away from the burst near a thermocouple.

Figure 3-12. SEM images of (a) the cross section and (b) the outside surface of the coating at a high strain location near the burst tip showing significant gaps in the coating and exposure of the substrate $\mathrm{Zr}$ material.

Figure 4-1. The modified burst test setup (a) and (b), and in schematic form (c), with crucial

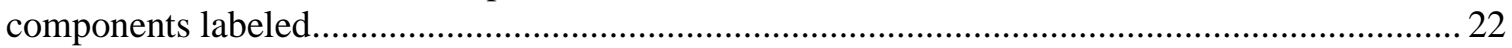

Figure 4-2. Pressures produced from the actuator displacement rates used in this work.......................... 23

Figure 4-3. Images taken of all four projections around $360^{\circ}$ of the MBT specimen circumference

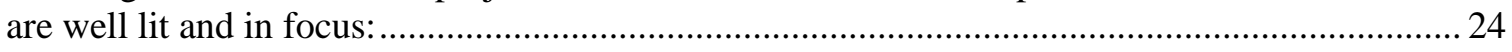

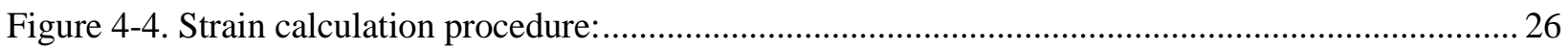

Figure 4-5. Schematic showing the postulated cause of the compression band near where the ballooning region begins.

Figure 4-6. DIC strain calculation for the Zry-4 specimen tested at room temperature and at 25.4 $\mathrm{mm} / \mathrm{s}$ actuator displacement rate showing how maximum strains and strain rate were calculated.

Figure 4-7. MBT results with $\mathrm{CrZr} 4$ showing the crack around the tube circumference near the edge of the balloon region, which occurred at all temperatures (top), and further separation of the coating from the cladding after the specimen cooled from $275^{\circ} \mathrm{C}$ to room temperature (bottom). No crack was present for any uncoated specimen. 


\section{LIST OF TABLES}

Table 2-1. Chemical composition and geometry of the used Zircaloy-4 cladding tubes ............................ 3

Table 2-2. Profilometer results for Zry-4 tubes (all measurements in microns) ....................................... 4

Table 3-2. Burst measurements taken from micrometer and Keyence microscope ( ............................ 16

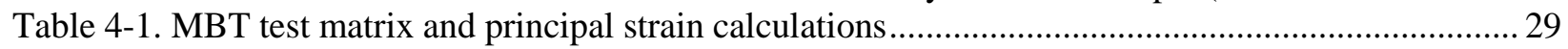

Table 4-2. Maximum first principal ( hoop) strains near the plane strain loading condition during the high strain rate portion of each test 


\section{ABBREVIATIONS}

AFC Advanced Fuels Campaign

AR as-received

ATF accident-tolerant fuel

BWR boiling water reactor

CP Cathcart-Pawal

DBA design-basis accident

DIC digital image correlation

DOE US Department of Energy

EDS energy dispersive x-ray spectroscopy

HFIR High Flux Isotope Reactor

HiPIMS high-power impulse magnetron sputtering

HZP hot zero power

IR infrared

LOCA loss-of-coolant accident

LWR light-water reactor

MBT modified burst test

OD outer diameter

ORNL Oak Ridge National Laboratory

PCMI pellet- cladding mechanical interaction

PVD physical vapor deposition

PWR pressurized water reactor

RIA reactivity insertion accident

RT room temperature

SATS Severe Accident Test Station

SEM scanning electron microscopy

TC thermocouple 



\section{ACKNOWLEDGMENTS}

This research was sponsored by the Advanced Fuels Campaign (AFC) Program of the US Department of Energy (DOE), Office of Nuclear Energy. The report was authored by UT-Battelle under Contract No. DE-AC05-00OR22725 with the US Department of Energy.

The authors would like to acknowledge Don Erdman for assistance in setting up the modified burst test (MBT) system. 



\section{SUMMARY}

This report summarizes the results of Advanced Fuels Campaign (AFC) accident-tolerant fuel (ATF) burst activities. Nuclear service grade Zry-4 was procured and coated with a 7-micron thick Cr coating. The coating quality was investigated, and there were several defects at the Cr/Zry-4 interface due to the surface roughness of the as received Zry-4 tubing. To provide insight into the effect of coating defects on the cladding performance under accident scenarios, the unirradiated uncoated and coated material was tested under loss of coolant accident (LOCA) and pellet cladding mechanical interaction (PCMI) reactivity insertion accident (RIA) conditions. The defected coating appeared to have no impact on the cladding performance under these scenarios when compared to the as-received cladding material. 



\section{FY21 AFC BURST ACTIVITIES WITH COATED ZIRCALOY-4 UNDER ACCIDENT CONDITIONS}

\section{INTRODUCTION}

The current goal of accident-tolerant fuel (ATF) material development is to improve reactor safety, especially during accident scenarios, and to boost the cost effectiveness of nuclear fuel in the reactor core by increasing the allowed burnup [1, 2, 3, 4]. Cladding materials are being developed as part of the ATF materials system. The leading candidates for these ATF cladding materials are $\mathrm{SiC} / \mathrm{SiC}$, iron-chromealuminum, and coated zirconium alloys. The industry's leading ATF cladding concept is coated zirconium alloys because the coating reduces the waterside oxidation rate and minimally affects core physics [1]. This is because reactors were designed for and have used uncoated zirconium alloys for years. However, before new cladding materials can be adopted for use in reactors, their performance under accident scenarios must be investigated to ensure that the coating preserves (i.e., do no harm) or improves the safety margins of its uncoated counterparts. In particular, this investigation must include cladding performance under transient accident scenarios such as the loss-of-coolant accident (LOCA) and the reactivity insertion accident (RIA). Oak Ridge National Laboratory (ORNL) completed a campaign to manufacture $\mathrm{SiC} / \mathrm{SiC}[5]$ and $\mathrm{FeCrAl}[6,7]$ and to investigate their performance under LOCA [8, 9] and RIA $[10,11]$. The leading ATF candidates in the industry are coated zirconium alloys, so it is important to continue that campaign and prioritize coated Zry testing.

During a LOCA, loss of primary coolant can result in increasing fuel and cladding temperatures. Subsequently, cladding internal pressure can rise, inducing increased stress on the cladding. Increased temperatures and reduced external pressures from a LOCA event can also initiate a phase change of the waterside coolant from liquid water to high-temperature steam, hindering heat transfer and creating a more aggressive oxidizing environment. The issues caused by steam oxidation are two-fold. First, the oxidation reaction is exothermic, which results in heat generation that creates a feedback loop of temperature increase $[1,2,3]$. Second, the oxidation process consumes the ductile metal cladding as it transitions to brittle oxide, thus embrittling the cladding. Moreover, hydrogen gas is produced as a byproduct of the oxidation reaction, which is known to ingress into the metal matrix and further embrittle the cladding. Eventually, until the fuel rods are quenched, the combination of increased internal overpressure, high temperature creep, and cladding embrittlement can cause the cladding tube to burst or break. To improve the safety margins of ATF materials under LOCA conditions, the design objective is to increase the coping time, which is the time that reactor personnel have to respond to an accident (i.e., quenching). This can be accomplished by developing oxidation-resistant cladding alloys that slow heat generation from oxidation, preserve the more ductile metal, and reduce hydrogen embrittlement. At ORNL, the Severe Accident Test Station (SATS) is used to evaluate cladding performance during a LOCA event by exposing the cladding specimen to a design-basis environment as expected from those accident conditions.

On the other hand, an RIA scenario can be initiated by a control rod drop in boiling water reactors (BWRs) or a control rod ejection in pressurized water reactors (PWRs), both of which would result in a local increase in fission rate density in the nuclear fuel $[3,12]$. Due to the increased fission rate, the temperature in the fuel rapidly rises, resulting in fuel expansion. Eventually, the fuel's expansion closes any fuel-cladding gaps and then induces a mechanical load onto the cladding. This condition is known as pellet-cladding mechanical interaction (PCMI). If the fuel's expansion causes some critical strain on the cladding, then it could rupture and potentially release fissile material. During PCMI, the fuel induces specific loading conditions on the cladding. For instance, due to the rapid pulse of fission rate density, the strain rates are expected to be up to $10 \mathrm{~s}^{-1}$ and within the range of operating temperatures (in the case of a fast pulse) and $\sim 800^{\circ} \mathrm{C}$. Above this point, departure from nucleate boiling becomes the primary failure 
mechanism [12]. Moreover, the cladding is expected to be at or near a plane strain tensile strain state, in which the ratio of the hoop strain to the axial strain is 1:0. Critically, cladding temperature and the loading biaxiality are known to impact the strain to failure, and classically, the strain rate is known to impact material ductility $[12,13,14,15,16]$. To that end, the modified burst test (MBT) $[16,17]$ is implemented to evaluate materials under the PCMI phase of RIA because (1) it imposes the plane strain state on the cladding specimen, (2) it can be run at operating temperatures, (3) it imposes the range of strain rates expected from PCMI, and (4) it can measure the hoop strain to failure that is typically used to evaluate RIA performance [18].

In this effort, systematic burst tests using ORNL's SATS system for simulated LOCA tests were performed on as-received (AR), uncoated nuclear-grade Zircaloy-4 (Zry-4) cladding, as well as a coated version of the same alloy. The SATS system was utilized to induce a typical design-based LOCA temperature history on each specimen under a steam environment. The parameters of burst pressure, burst temperature, size of burst measurements, and oxide layer thickness measurements were used to compare LOCA performance between the alloys. In addition, ORNL's MBT system was used to test both alloys at $275^{\circ} \mathrm{C}$ and room temperature (RT) under PCMI-relevant strain rates. The specimens' outer surfaces were spray-painted with a speckle pattern, and digital image correlation (DIC) [19] was used to measure hoop strain at failure to evaluate PCMI performance. For both tests, the performance of the coated material was investigated by microscopy, and it was determined that the coated cladding performed as well as or better than the uncoated material.

\section{MATERIALS}

\subsection{ZIRCALOY-4 CLADDING MATERIAL}

Zry-4 was developed from Zircaloy-2, with the goal of reducing hydrogen pick up hydrogen in a PWR by reducing the amount of nickel and decreasing the allowed range of iron in the alloy [20]. Since then, a few more incrementally optimized zirconium-based alloys have been developed and are used in nuclear reactors. However, Zry-4 is still widely used as a standard for nuclear research due to its large database of well-characterized material properties for comparison, its relative lack of proprietary restrictions, and its relative similarity to the newer Zr-based alloys.

ORNL procured several hundred meters of Zry-4 from Cameco Fuel Manufacturing (Port Hope, Ontario, Canada) in FY20. The material was stress relieved annealed and conformed to the typical geometry of a PWR cladding, conforming to ASTM B353-12 with a surface finish of 0.81 micrometer R-average (Ra) or better [21]. Product certifications are on file at ORNL. The tubes were cut into $\sim 300 \mathrm{~mm}$ segments for handling purposes. The geometry and chemical composition of Zircaloy-4 tubes are shown in Table 2-1. A piece of Zry-4 in its AR condition is shown on the left-hand side of Figure 2-1 at three magnifications to highlight macroscopic scratches on the surface. The right side of Figure 2-1 displays two scanning electron microscopy (SEM) images of the tubes' surfaces. The images show several microscopic defects and trenches which were introduced during tube manufacturing or transport. 
Table 2-1. Chemical composition and geometry of the used Zircaloy-4 cladding tubes

\begin{tabular}{lc}
\hline \multicolumn{1}{c}{ Parameter } & Zircaloy-4 $^{b}$ \\
\hline Length, mm & 304.8 \\
Outside diameter, mm & 9.50 \\
Wall thickness, mm & 0.56 \\
Zr, wt.\% & Balance \\
Sn, wt.\% & $1.20-1.45$ \\
Fe + Cr + Ni, wt.\% & 0.37 (no Ni) \\
Cr, wt.\% & $0.07-0.13$ \\
Ni, wt. $\%$ & - \\
\hline
\end{tabular}

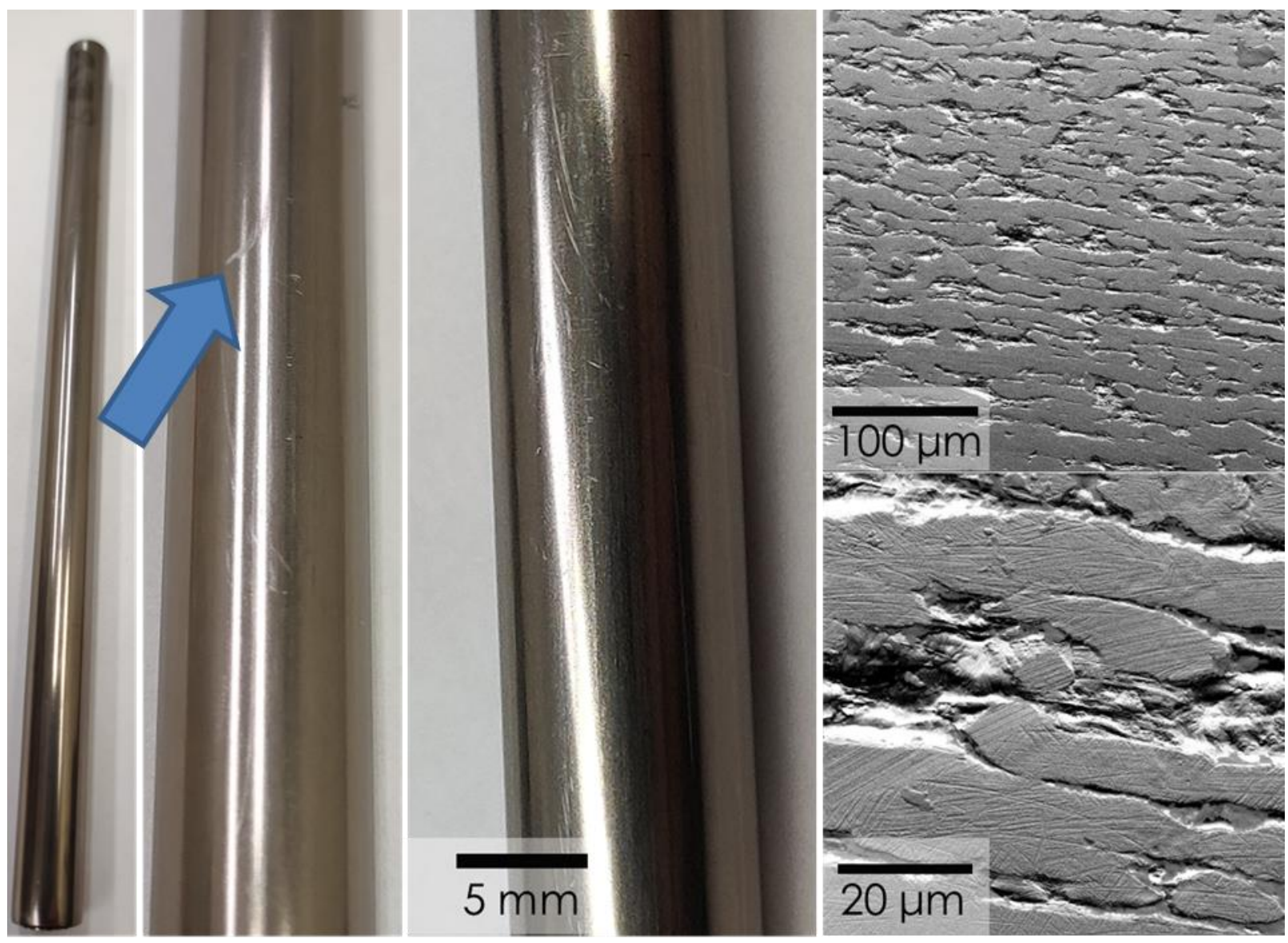

Figure 2-1. Macro- and microscopic images of the surface of Zry-4 tubes in as-received condition. The arrow indicates the large scratch on the specimen surface that was specifically included in surface roughness analysis. SEM images on the right show the surface roughness with several scratches/trenches with widths of approximately 2 micrometers.

The surface of the tube was measured using a profilometer to confirm the roughness values are within the specifications of the vendor. The profilometer measurements were performed with a Mahr MarTalk profilometer using the MarWin software package. Each measurement was across a length of $4 \mathrm{~mm}$, and 11,200 points were measured using a speed of $0.5 \mathrm{~mm} / \mathrm{s}$. The tubes were measured in different areas (across a large scratch seen in Figure 2-1, in the center, and close to the end of the tube) to identify possible differences. The results are shown in 
Table 2-2, and the roughness plots are shown in Figure 2-2. It should be noted that the scale of the bottom surface roughness plot was changed to accommodate the large depth of the scratch. Based on these results, it was clear that the surface roughness, Ra, was within the specified limit of 0.81 micrometers, but in general, maximum roughness peaks (Rmax) of approximately 2 microns could be seen. Moreover, analysis of the visible scratch on the surface revealed an Rmax peak of 4.9 microns, which is more than twice the Rmax of the remainder of the tube. This large scratch suggests that using only Ra as the roughness parameter is not enough to characterize the surface quality, especially if it impacts coating adherence or causes the coating to crack.

Table 2-2. Profilometer results for Zry-4 tubes (all measurements in microns)

\begin{tabular}{cccccc}
\hline Sample & Position & R-average & $\begin{array}{c}\text { Rz - peak- } \\
\text { valley }\end{array}$ & Rmax & $\begin{array}{c}\text { Rp -max profile } \\
\text { height }\end{array}$ \\
\hline Uncoated tube & Center & 0.3264 & 1.9717 & 2.1239 & 0.5139 \\
& Outside & 0.2370 & 1.9087 & 2.1393 & 0.3641 \\
& Visible dent & 0.3614 & 3.2259 & 4.8854 & 0.7955 \\
\hline
\end{tabular}

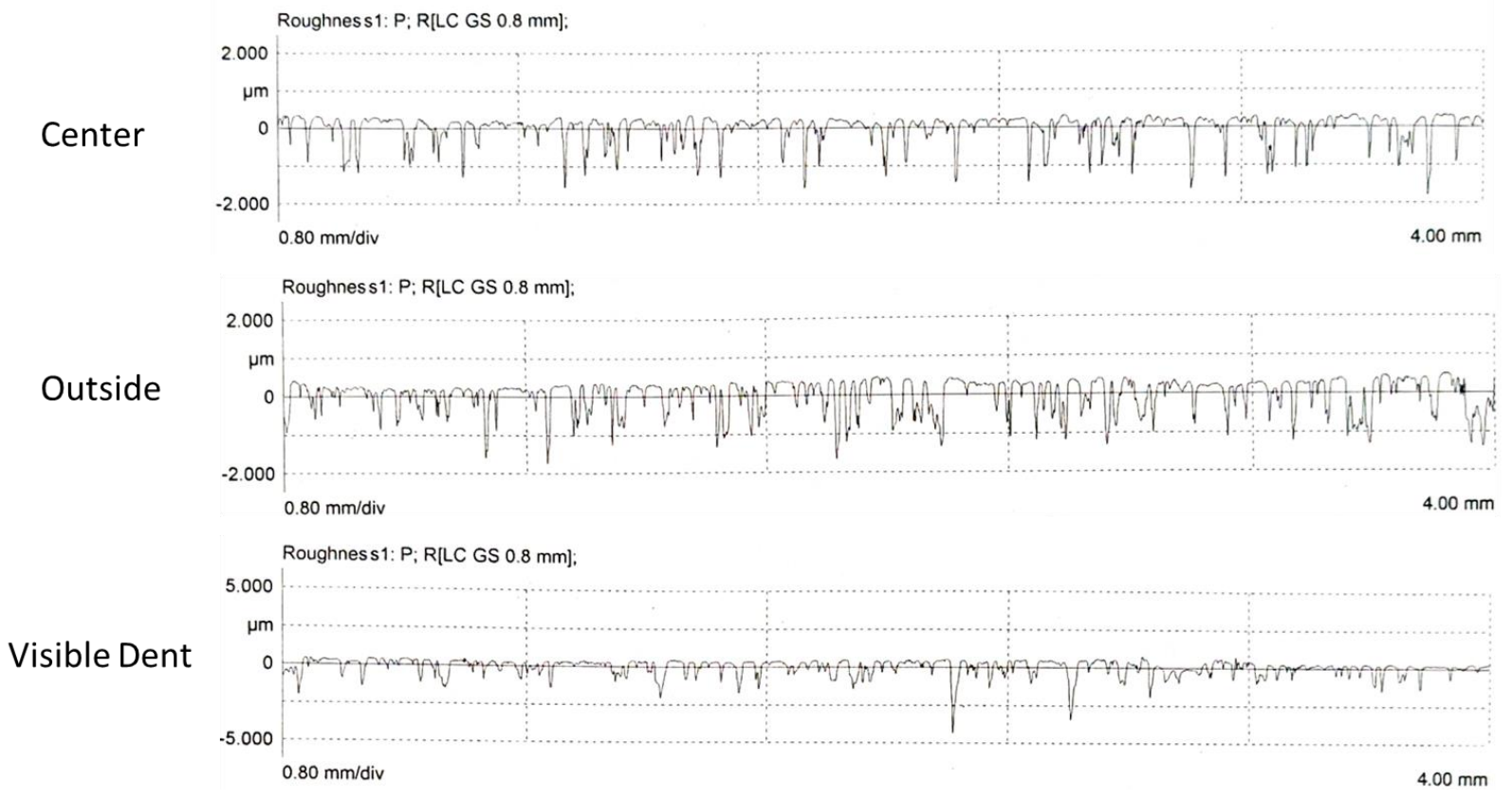

Figure 2-2. Surface roughness of the three locations of the tube.

\subsection{CR-COATINGS ON CLADDING TUBES}

Twenty $\sim 300 \mathrm{~mm}$ tubes were sent to Acree Technologies, Inc., in California, to be coated with a 7 micron thick $\mathrm{Cr}$ coating. The $\mathrm{Cr}$ coating was applied using a high-power impulse magnetron sputtering (HiPIMS) process. This process utilizes high-peak power densities in short pulses between a couple and a few hundred microseconds with a low-duty cycle below $10 \%$. This process enables higher densities of coatings, but it reduces the coating growth rate. Before the coating process, the $\sim 300 \mathrm{~mm}$ Zry- 4 tubes were cleaned using an ultrasonic cleaner and isopropanol. Then, the tubes were mounted to the physical vapor deposition (PVD) coating machine, and a plasma cleaning step was conducted to further clean the surfaces of the cladding tubes. After plasma cleaning, the HiPIMS coating process was performed. The power density was $9.9 \mathrm{~W} / \mathrm{cm}^{2}$, the applied bias voltage during the coating process was $-35 \mathrm{~V}$, and the temperature was $150^{\circ} \mathrm{C}$. 
The tubes in AR and coated conditions are shown in Figure 2-3. Small samples were cut from the coated tubes, polished, and investigated using SEM techniques to observe the coating thickness and quality. The results are shown in radial direction in Figure 2-4 and in axial direction in Figure 2-5. Both figures show that the coating is not adhering to the cladding material and is cracked in several locations. It was determined that the cladding surface was too rough for the coating to overgrow those surface defects. The very directional growth of the coating visible in the inset in Figure 2-5 indicates that the coating is located in zone 1 of the generalized structure zone diagram [22]. The coating was measured to have an average thickness of 4.75 microns, with a maximum deviation of 0.15 microns in the areas that were not destroyed or ablated.
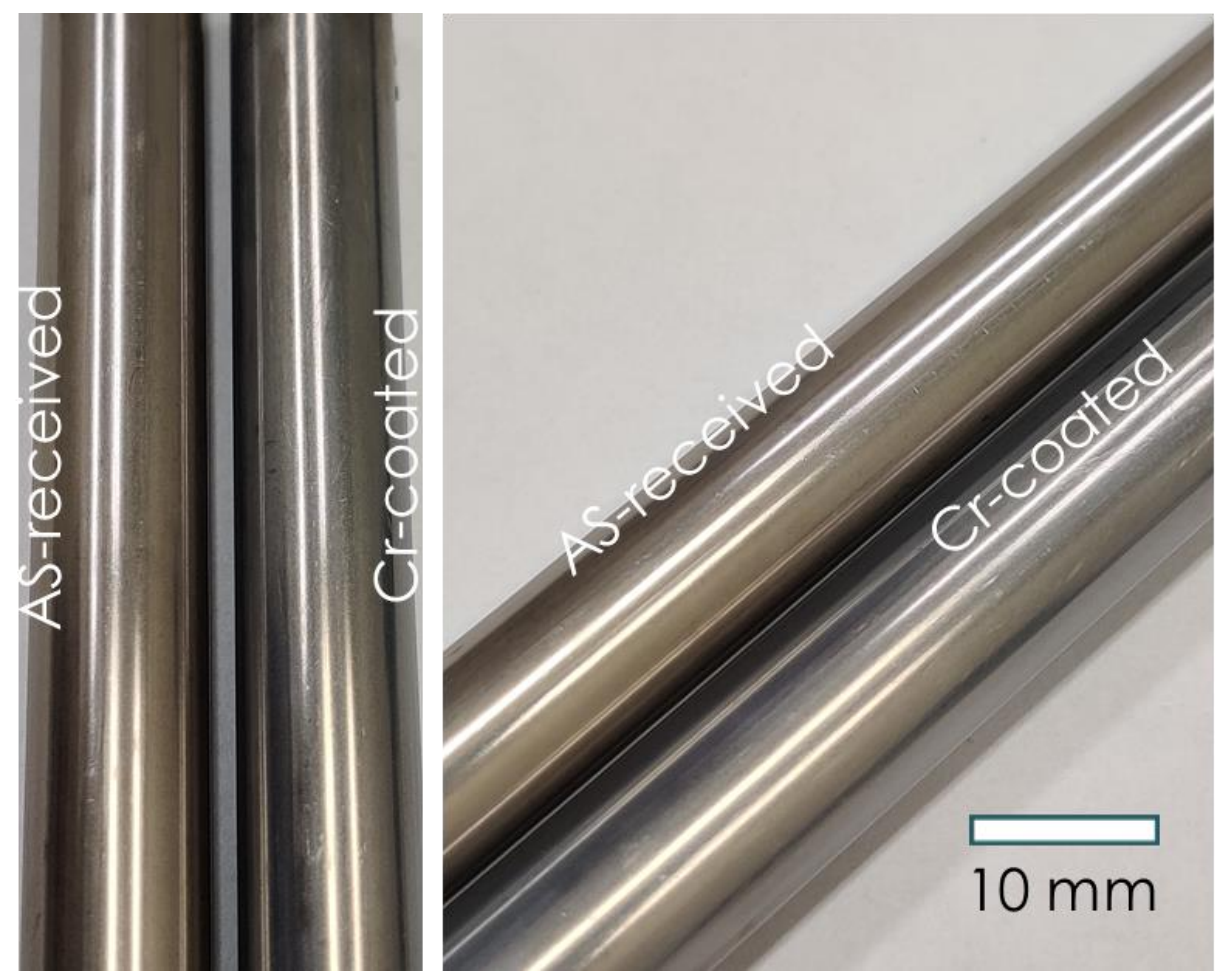

Figure 2-3. As-received and Cr-coated tubes for comparison. 


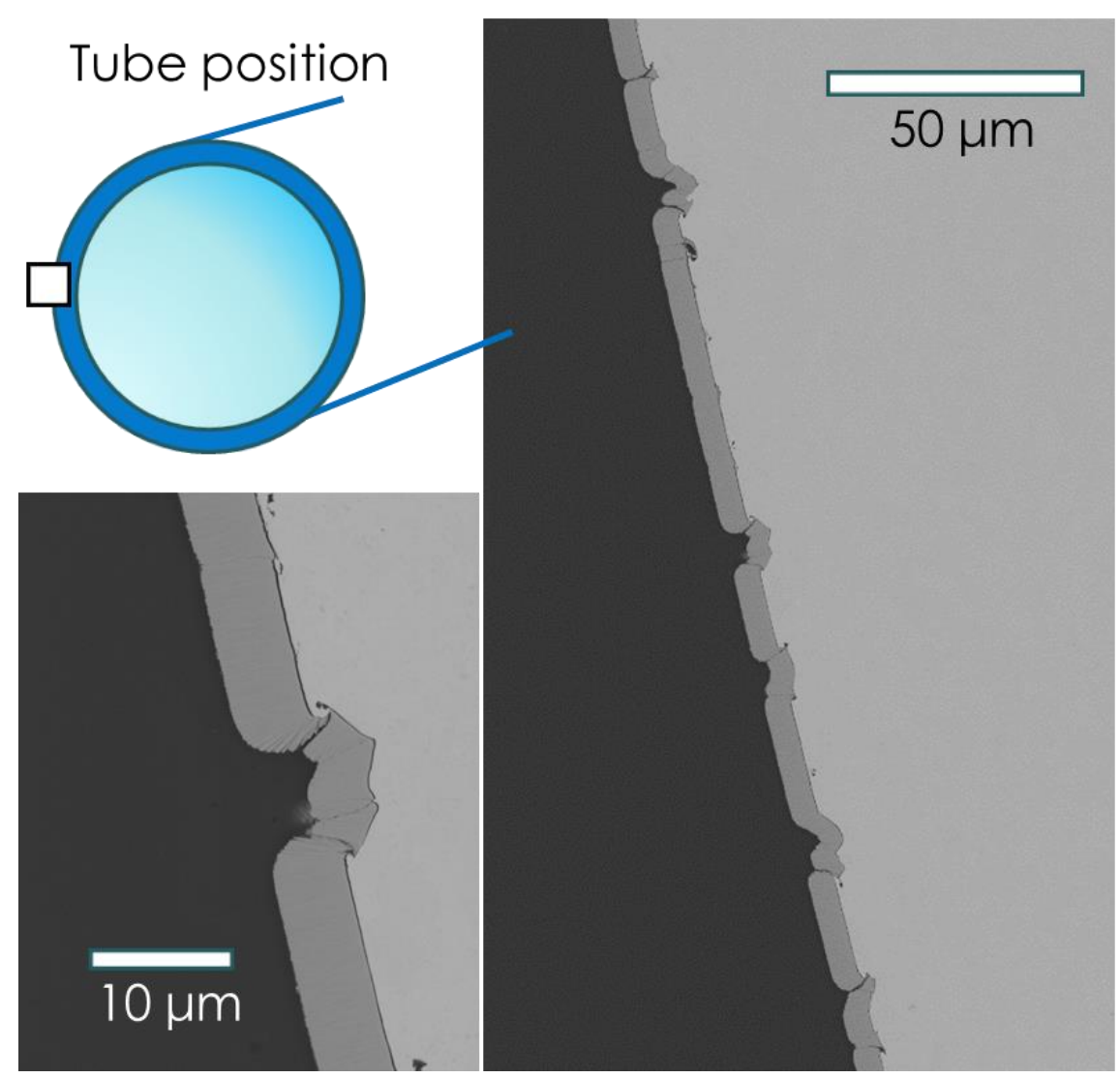

Figure 2-4. Cr-coated Zry-4 cladding tubes cut in radial direction, as observed using SEM.

Although the surface roughness defects already precluded a high-quality coating, adjustments to the HiPIMS process are also recommended. Specifically, a higher temperature could help to increase the $\mathrm{Cr}$ mobility, which helps with overgrowing defects [23]. Even though the energy density was very high, the voltage bias must be increased to change the stress in the coating from tensile to compressive stress [23]. Furthermore, using a lower frequency can result in a reduced deposition rate, which can also help to form a more adherent coating [24]. Applying the mentioned parameters to introduce a compressive stress can help to prevent crack opening during operating cycles. This cracking is caused by the different coefficients of thermal expansion between the coating and cladding material. However, if compressive stress is too high, ablation of the coating material can result and needs to be prevented. Therefore, finding the ideal parameters for the HiPIMS coating process is crucial, despite how difficult it is due to the parameters being dependent on each other, very sensitive, and unique to each coating device and material.
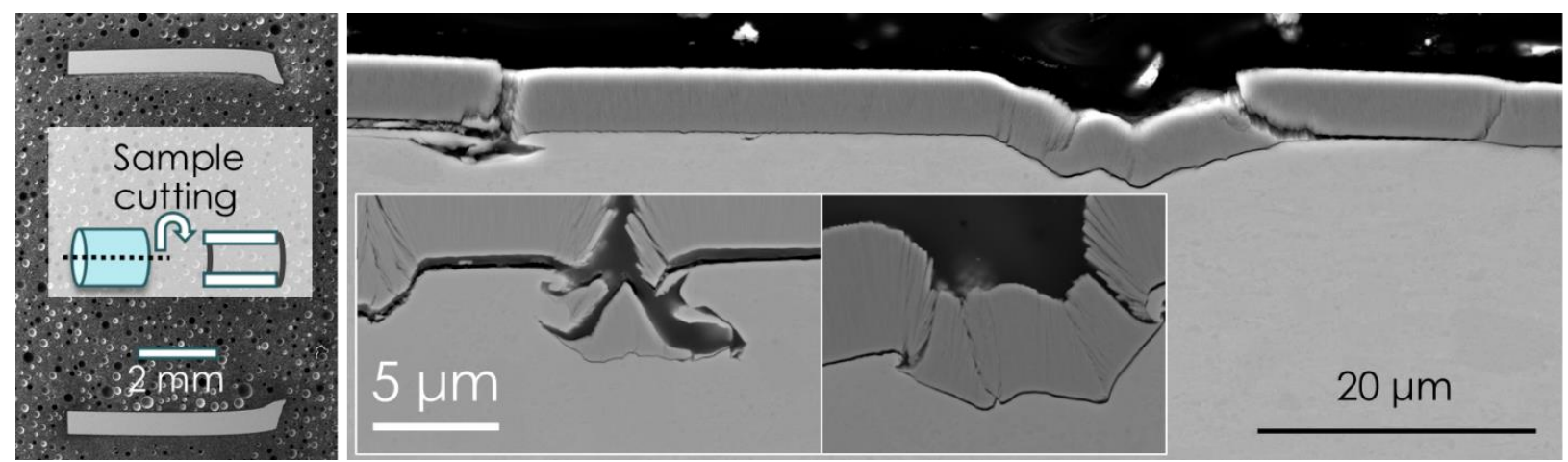

Figure 2-5. Cr-coated Zry-4 cladding tubes cut in axial direction, as observed using SEM. 
Despite the coating showing multiple serious defects, it is still beneficial to test the coated material under accident conditions because to obtain insight into how a defected coating would perform under those conditions. To elaborate, if a high-quality, low-defect coating were produced and scaled up to industrylevel production, then there is a reasonable likelihood that some defects would result in the coated tubes, although they would be much less than those seen in this material. The ways that coating defects impact the cladding performance must be understood so those situations can be avoided or accounted for in licensing criteria and during operation.

\section{SEVERE ACCIDENT TEST STATION}

\subsection{BURST TESTING EXPERIMENTAL DESIGN}

Burst testing was conducted using ORNL's ex-reactor integral LOCA furnace system located in Room B151, Building 4500S on ORNL's Oak Ridge, Tennessee, campus. The integral LOCA furnace is shown in Figure $3-1$, with primary components detailed as follows, from the top.

- A calibrated analog pressure gauge is used to measure and set the initial internal overpressure of the cladding train assembly at room temperature prior to initiating the test sequence.

- Four type $\mathrm{S}$ thermocouples, calibrated prior to use, are used to monitor and control cladding temperature during testing.

- The test chamber that houses the cladding train assembly and thermocouples is a custom constructed, high-temperature quartz reaction tube which contains the steam environment.

- A quench tank houses de-ionized water that floods the entire test chamber at the conclusion of testing.

- A pressure relief tank is used to condense steam after it leaves the test chamber. The test chamber sits inside an infrared (IR) furnace.

- At the bottom of the test chamber, an inlet line provides steam into the test environment, and another inlet line is used to water cool the IR furnace. 


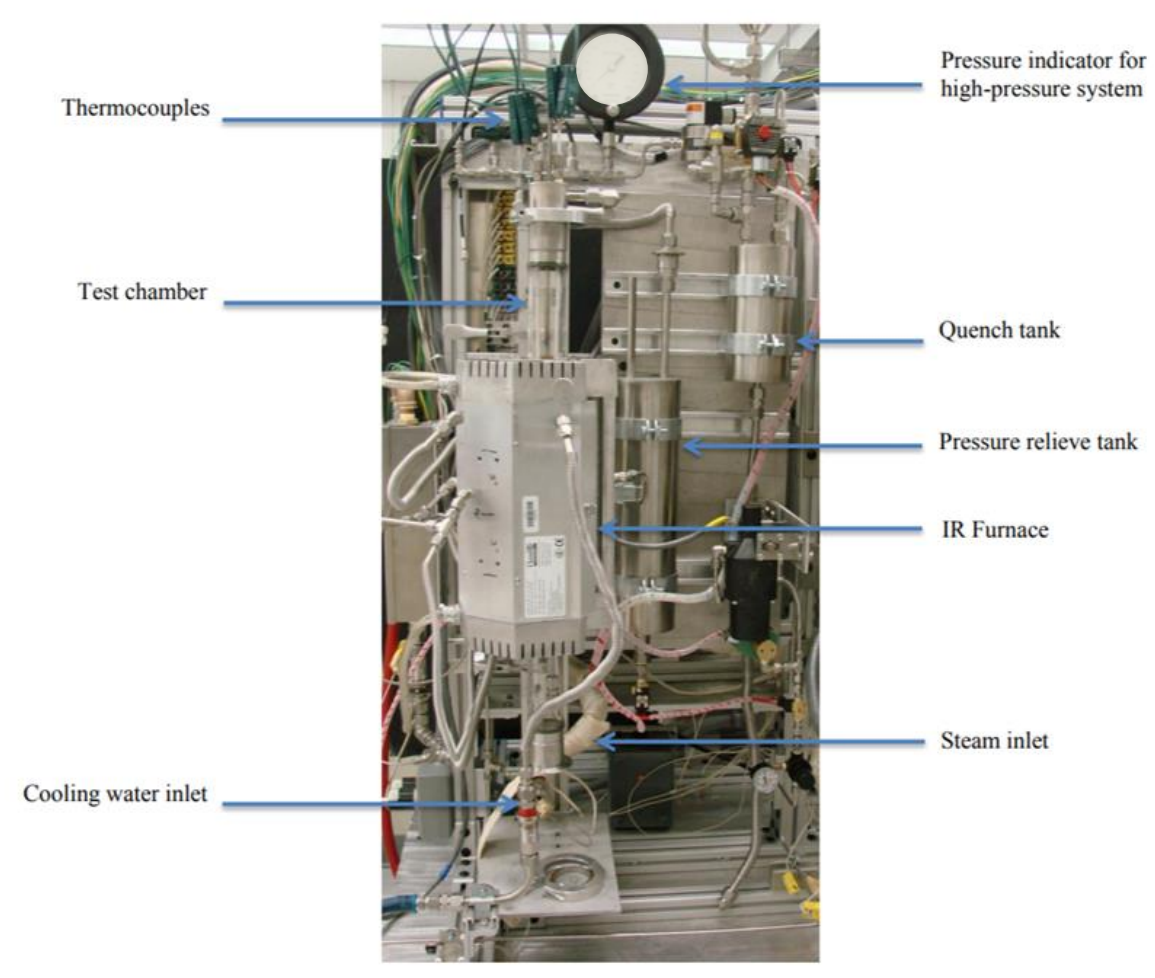

Figure 3-1. Integral LOCA furnace with primary components indicated.

The test chamber and components are shown in Figure 3-2. A calibrated pressure transducer was used to monitor the internal pressure of the tube assembly during the test. In tests conducted for this effort, the measured pressure difference between the transducer and the exterior analog gauge was always less than $1 \%$ and was commonly found to be $\sim 0 \mathrm{psi}$. A high-pressure line was used to internally pressurize tubes with Ar prior to the test sequence. A steam outlet was located at the top of the test chamber to prevent build-up of steam pressure. As mentioned previously, the test chamber itself was a quartz tube with an outer diameter (OD) of $50 \mathrm{~mm}$. The cladding train assembly was connected to the high-pressure line via stainless-steel Swagelok compression fittings. An additional stainless-steel Swagelok compression fitting was used at the end of the cladding train assembly. Two perforated spacers were welded to the Swagelok connections to limit movement of assembly during testing and to center the cladding train assembly. The end of the test chamber was sealed with a stainless-steel flange and O-ring. The length of the cladding was $\sim 300 \mathrm{~mm}$. For all specimens, three thermocouples were placed on the back of the tube: one $\sim 50 \mathrm{~mm}$ above centerline, one at centerline, and one $\sim 50 \mathrm{~mm}$ below centerline. Additionally, a fourth thermocouple was placed at centerline on the front of the specimen. More specimens were placed on the back of the tube because that was the location of failure for most tests. The back centerline thermocouple was used as the control thermocouple. 


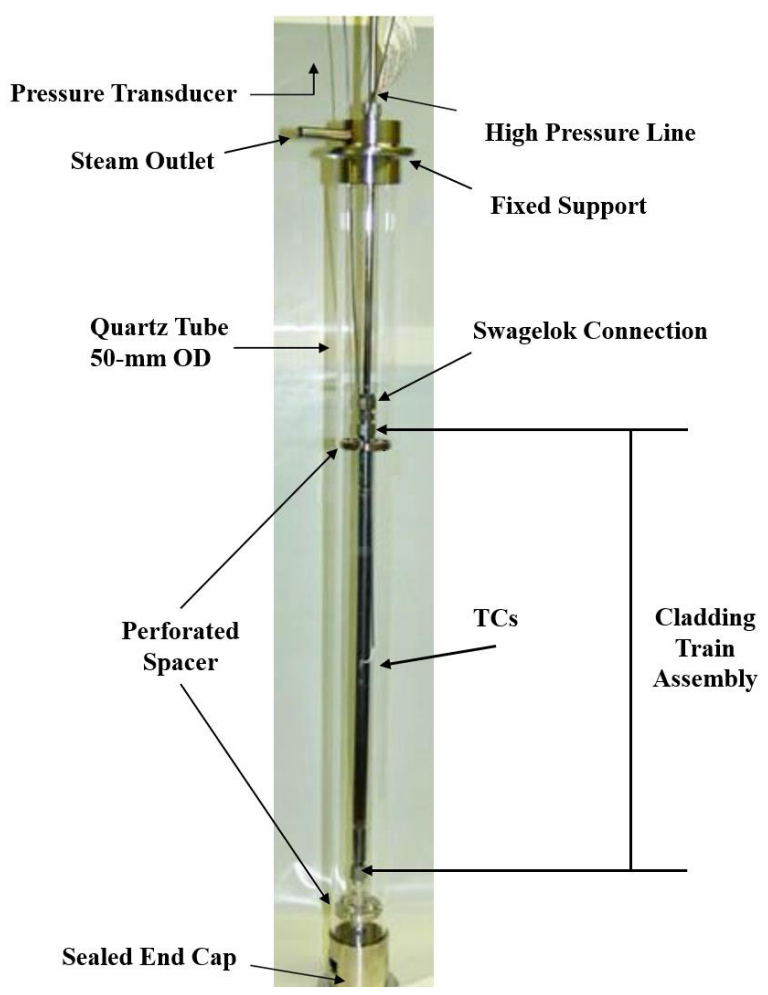

Figure 3-2. Test chamber situated inside the IR furnace during LOCA experiment with components indicated.

Figure 3-3 shows a cladding train assembly prior to testing. As seen in the figure, both ends of the cladding were terminated with a stainless-steel Swagelok with perforated stainless-steel spacers to prevent the cladding from moving and colliding with the test chamber during testing. The cladding contained an alumina filler rod to better simulate the ratio of thermal mass and volume among the fuel, internal gas, and cladding in the furnace hot zone. It should be noted that in the reactor, the fuel cladding gap is not always constant, and in some cases the fuel can be fragmented or bonded to the inside surface. Although a filler rod cannot perfectly simulate those boundaries, it is expected to be more realistic than an empty cladding tube filled with only gas. 


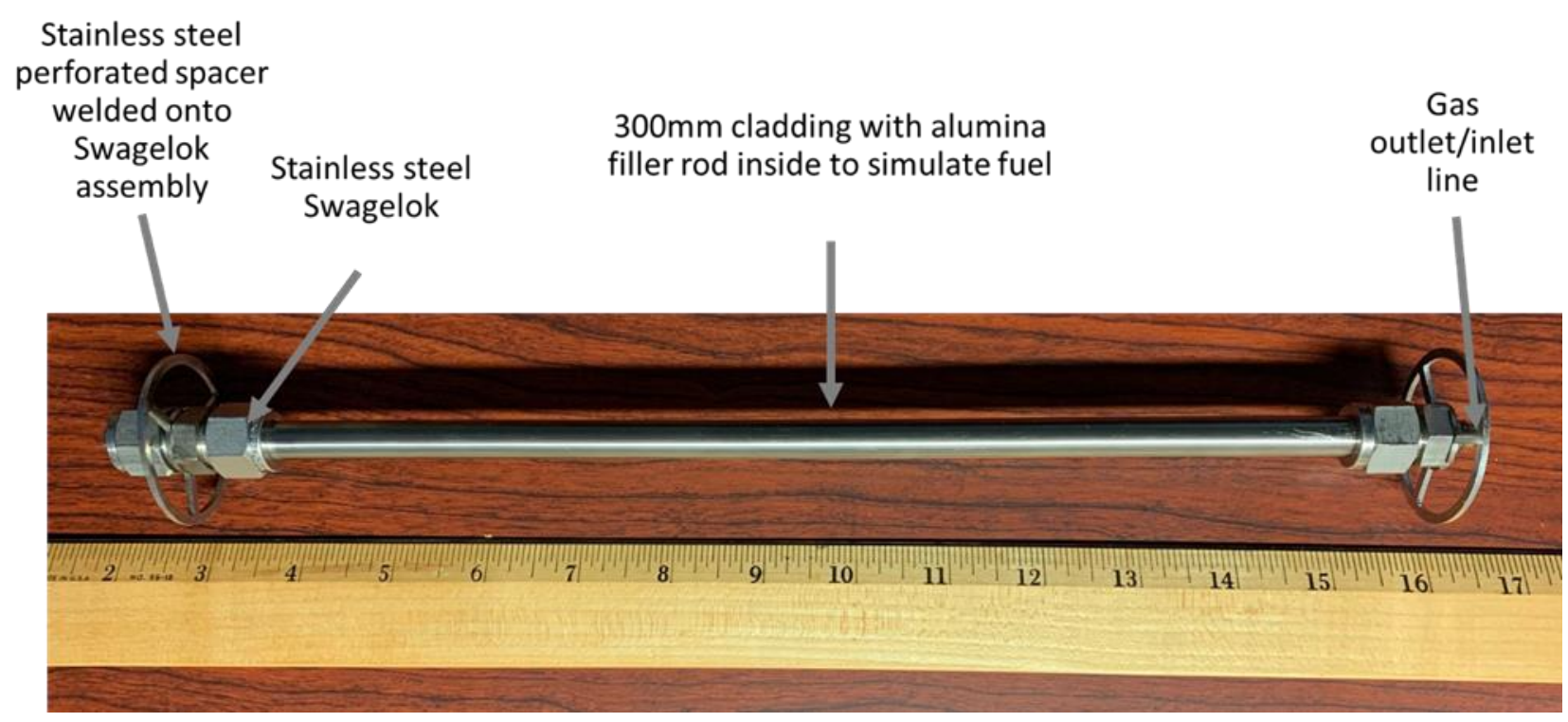

Figure 3-3. Cladding train assembly situated inside test chamber.

A typical pressure and temperature profile during LOCA testing is presented in Figure 3-4a. The initial stage consisted of heating the internally pressurized cladding to $100^{\circ} \mathrm{C}$, followed by a $120 \mathrm{~s}$ hold to allow the cladding assembly to be checked for pressure leaks. During this stage, steam was introduced to the test chamber. Then the cladding assembly was heated to $300^{\circ} \mathrm{C}$ at $5^{\circ} \mathrm{C} / \mathrm{s}$, followed by a $300 \mathrm{~s} \mathrm{hold} \mathrm{to}$ allow for the setup to reach thermal equilibrium, which simulates reactor temperature prior to the LOCA temperature ramp. Following the $300^{\circ} \mathrm{C}$ soak, cladding was heated at $5^{\circ} \mathrm{C} / \mathrm{s}$ to a maximum temperature of $1,200^{\circ} \mathrm{C}$. During this temperature ramp, cladding burst occurred and was dependent on the initial pressure of the tube and temperature. The temperature ramp continued, regardless of when burst occurred. After reaching $1,200^{\circ} \mathrm{C}$, temperature was held for $300 \mathrm{~s}$ before the IR furnace powered down. After air cooling to $600^{\circ} \mathrm{C}$, the test chamber was quenched with water. After testing, a profile similar to that shown in Figure 3-4a was analyzed to determine temperature and pressure at time of burst. Cladding burst is signaled by the sudden significant loss of pressure (small pressure drops are expected to represent ballooning before burst), and the temperature of the closest thermocouple to burst at that time is taken as the burst temperature. It was found that a temperature drop occurred immediately following the burst, which was likely caused by movement of the tube after burst or the flow of argon outside the hot zone cooling the tube as it escapes. Regardless of the mechanism, it was determined that this temperature drop was not indicative of the true burst temperature. This determination is further evidenced by the quick recovery of the cladding temperature after the movement and/or gas flow stops. Based on this temperature drop, the burst temperature was calculated by continuing the temperature ramp to the time of the significant pressure drop. The temperature drop and burst temperature calculation are shown in Figure 3$4 b$.

The engineering hoop stress $\left(\sigma_{\mathrm{s}}\right)$ is calculated as

$$
\sigma_{\mathrm{s}}=\Delta \mathrm{P}\left(\mathrm{r}_{\text {inner }} / \mathrm{t}_{\mathrm{wall}}\right)
$$

where $\Delta \mathrm{P}$ is the pressure difference between the external and internal cladding, $\mathrm{r}_{\text {inner }}$ is the inner mean radius of the AR cladding, and $t_{\text {wall }}$ is the nominal wall thickness of the AR cladding. OD and wall thickness were measured with calibrated digital Mitutoyo calipers $( \pm 0.015 \mathrm{~mm})$. The average OD and wall thicknesses of both bare $\mathrm{Zr} 4$ and $\mathrm{Cr} / \mathrm{Zr} 4$ were $9.52 \pm .01 \mathrm{~mm}$ and $0.58 \pm .01 \mathrm{~mm}$, respectively. The engineering hoop stress at burst was calculated using the burst pressure determined from the 
temperature/pressure profile. Burst testing was performed on bare $\mathrm{Zr} 4$ at approximate initial internal overpressures of 5.5, 8.3, and 9.6 MPa, and at 4.1, 5.5, 8.3, and 9.6 $\mathrm{MPa}$ for $\mathrm{Cr}$-coated $\mathrm{Zr} 4(\mathrm{Cr} / \mathrm{Zr} 4)$.

(a)

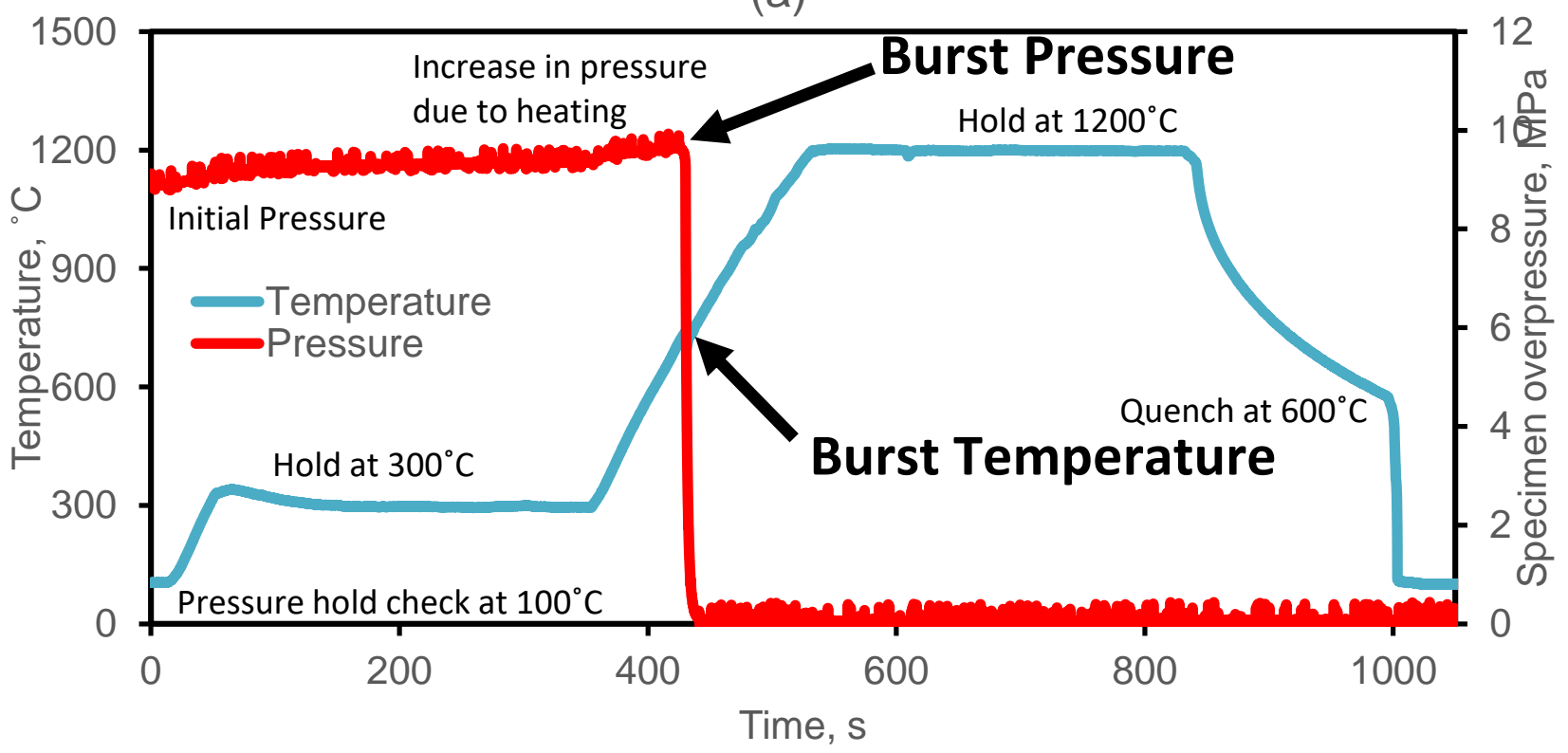

(b)

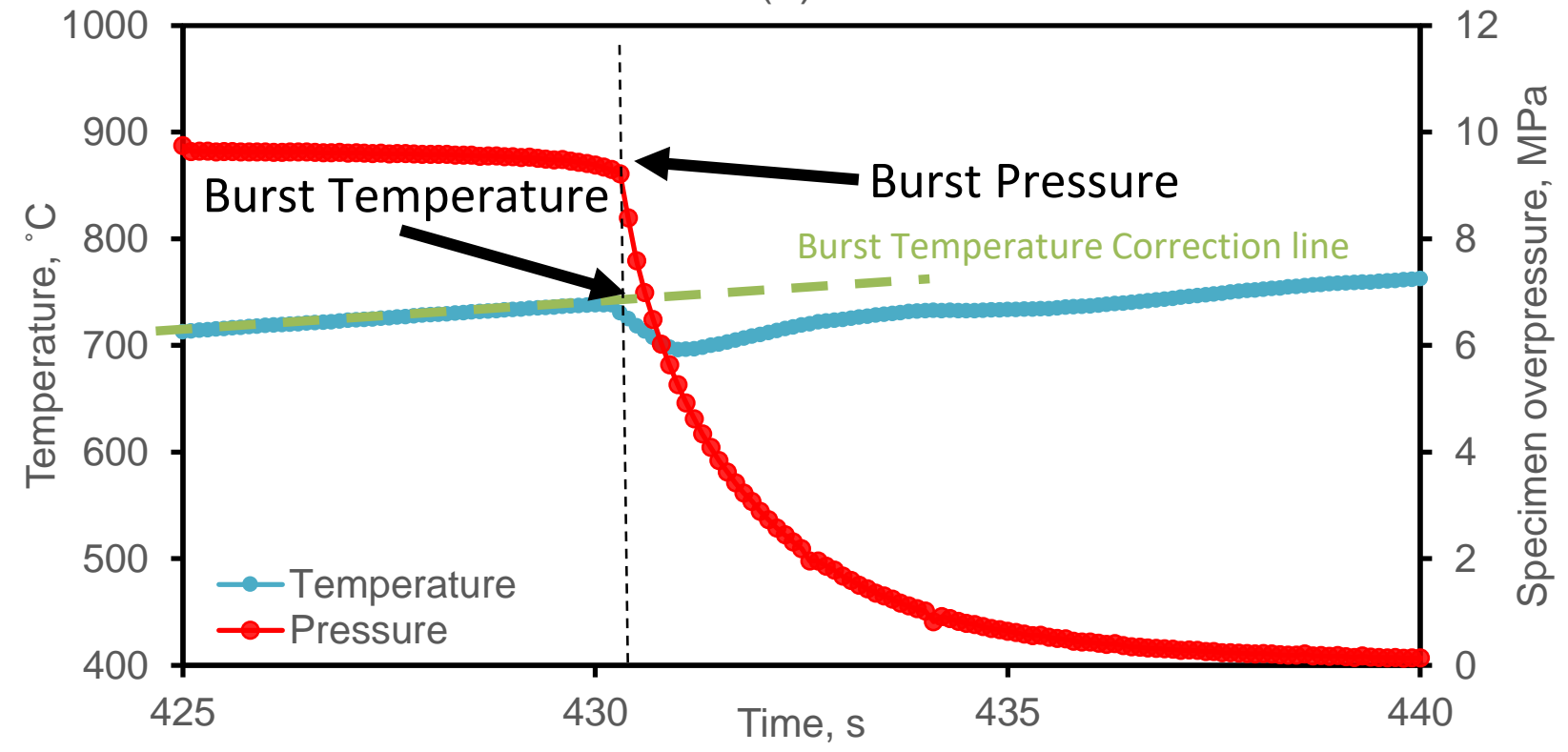

Figure 3-4. (a) Temperature and pressure profiles during LOCA burst testing of Zry-4 cladding coated with Cr at an approximate initial overpressure of $8.3 \mathrm{Mpa}$; (b) close-up of data showing where burst pressure and temperature are taken.

\subsection{LOCA BURST TESTING RESULTS AND ANALYSIS}

The relationship between burst temperature and burst pressure is shown in Figure 3-5(a), and the relationship between burst temperature and burst engineering hoop stress, as calculated using Eq. (1) is 
given in Figure 3-5(b) for both bare Zry-4 and Cr-coated Zry-4 (Cr/Zr4). For reference, the Chapman correlation line (shown in gray) was obtained from a variety of similar burst experiments and is indicative of the general burst stress behavior of nuclear-grade $\mathrm{Zr}$ alloys [25, 26]. As can be seen, the burst hoop stresses of both Zry-4 and Cr/Zr4 are nearly indistinguishable from each other and the historical reference data set. Previous burst testing of Zircaloy-2 (not reported here) yielded similar results. Because the measured AR cladding geometry was identical between bare $\mathrm{Zr} 4$ and $\mathrm{Cr} / \mathrm{Zr} 4$, both Figure 3-5(a) and

Figure 3-5(b) are exactly proportional: hoop stress is burst pressure normalized to cladding geometry, as shown in Eq. (1). These results can be found intabular form in Table 3-1, which also includes the average temperature of all four thermocouples over the five seconds before the $1,200^{\circ} \mathrm{C}$ ramp started, as well as the average pressure over the same five seconds. The present study found that the $\mathrm{Cr}$ coating has no clearly discernible effect on either improving or worsening the relationship between burst pressure/stress and burst temperature. It can be explicitly stated that $\mathrm{Cr}$ coatings are envisioned to provide additional coping time during a design-basis accident (DBA) LOCA by mitigating increases in core temperature, because $\mathrm{ZrO}_{2}$ formation is highly exothermic [1], and therefore, $\mathrm{Cr}_{2} \mathrm{O}_{3}$ formation is preferable. Due to the lower heat generation and oxidation, the temperature increase is expected to be slower, and the amount of hydrogen produced by the oxidation is expected to be lower. These mechanisms are not reflected in the current ramp testing, because cladding heating is provided externally by a pre-programmed IR furnace, and the temperature is controlled to follow the same temperature profile. In general, if less heat is generated by the specimen, then more heat will be generated by the furnace to follow the LOCA temperature history.

Table 3-1. Temperatures and pressures at the beginning of the ramp and at burst for the SATS tests with bare Zry-4 and 7-micron Cr-coated Zry-4.

\begin{tabular}{llllll}
\hline Specimen & $\begin{array}{l}\text { Average temp. } \\
\text { over 5 s before } \\
\text { ramp (all TCs) }\end{array}$ & $\begin{array}{l}\text { Average } \\
\text { pressure 5 s } \\
\text { before ramp }\end{array}$ & $\begin{array}{l}\text { Burst temp. (from } \\
\text { TC nearest burst) } \\
\text { and burst location } \\
\text { (always centerline) }\end{array}$ & $\begin{array}{l}\text { Other temperatures at } \\
\text { burst (opposite side at } \\
\text { center, 50 mm above, } \\
50 \text { mm below) }\end{array}$ & $\begin{array}{l}\text { Burst } \\
\text { pressure }\end{array}$ \\
\hline Bare Zry-4 & 307 & $\mathrm{MPa}$ & ${ }^{\circ} \mathrm{C}$ (location) & ${ }^{\circ} \mathrm{C}$ & $\mathrm{MPa}$ \\
Bare Zry-4 & 284 & 6.16 & 756 (Back) & $776,736,795$ & 6.28 \\
Bare Zry-4 & 294 & 9.34 & 725 (Back) & $715,652,660$ & 9.72 \\
$\mathrm{CrZr4}$ & 290 & 10.8 & 679 (Back) & $674,653,679$ & 11.0 \\
$\mathrm{CrZr4}$ & 279 & 5.73 & 860 (Back) & $826,808,837$ & 4.83 \\
$\mathrm{CrZr4}$ & 290 & 9.71 & 793 (Back) & $847,762,735$ & 5.73 \\
$\mathrm{CrZr4}$ & 280 & 10.9 & 739 (Front) & $708,659,735$ & 9.21 \\
\hline
\end{tabular}


(a)

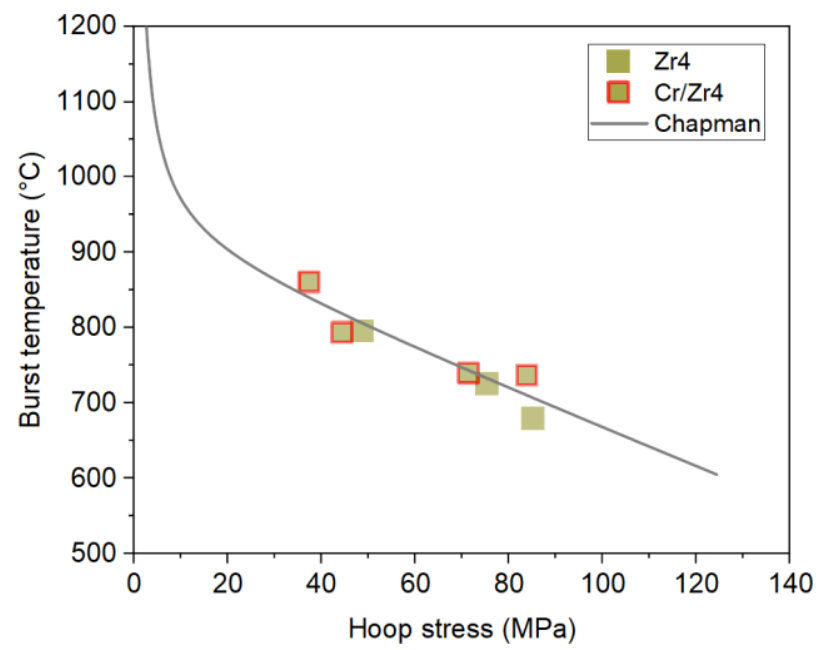

(b)

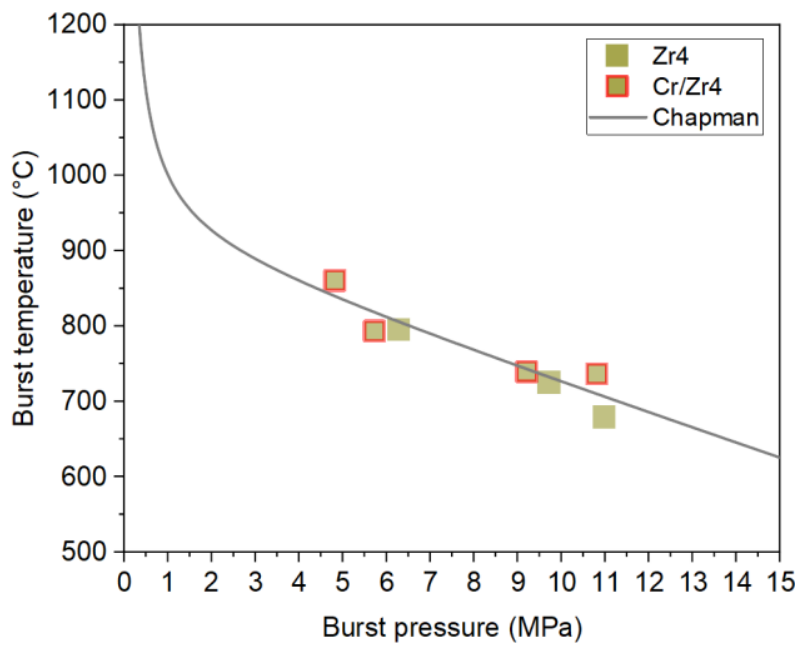

Figure 3-5. Relationship between burst temperature vs. (a) hoop stress and (b) burst pressure.

Images of the fuel cladding after burst testing are shown in Figure 3-6; Zry-4 is in the top row, and $\mathrm{Cr} / \mathrm{Zr} 4$ is in the bottom row. After burst testing, $\mathrm{Cr} / \mathrm{Zr} 4$ cladding acquired a green hue from $\mathrm{Cr}_{2} \mathrm{O}_{3}$ formation. The rate of $\mathrm{Cr}$ steam oxidation was at least an order of magnitude lower than the rate of $\mathrm{Zr}$ steam oxidation [27], potentially resulting in not only lower rates of temperature increases during a LOCA [28], but also lower amounts of $\mathrm{H}_{2}$ generation [29]. As can be seen by comparing burst locations in Figure 3-6, ballooning and subsequent burst mostly occurred in the same approximate location, indicative of a consistent hot spot in the IR furnace. Burst was observed to occur mostly in this region and has been consistent across multiple studies. 


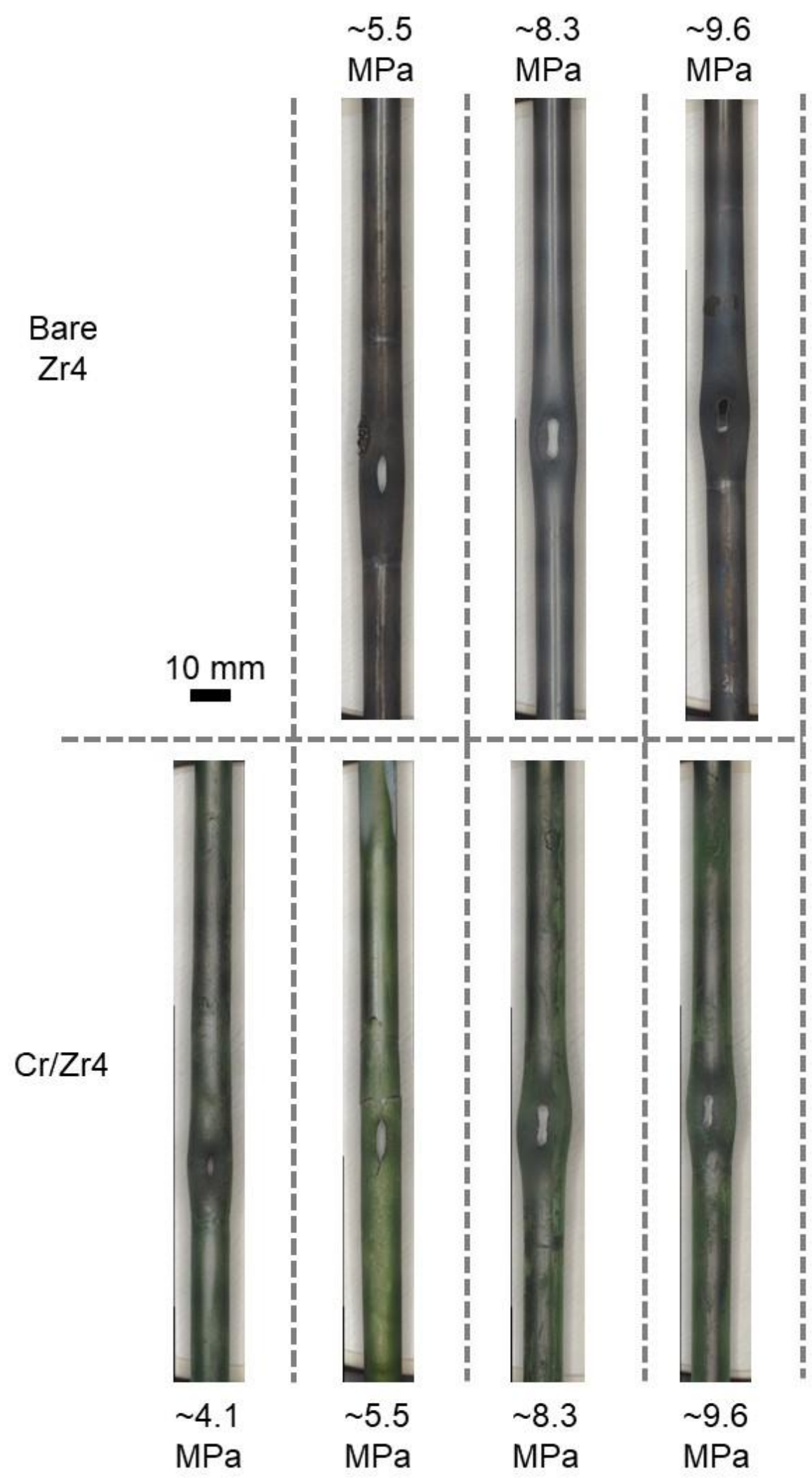

Figure 3-6. Optical macrographs of burst (top row) $\mathrm{Zr} 4$ and (bottom row) $\mathrm{Cr} / \mathrm{Zr} 4$ cladding. Each macrograph is labeled with the approximate initial overpressure. 
Burst opening length and burst opening width were measured using a Keyence-5000 and by traditional caliper measurements for comparison. The results of those measurements are shown in Table 3-2. To measure the burst opening length and width, the Keyence instrument was focused on the burst lips and the parallel line plane measurement tool in the Observe feature of the live image (no 3D construction was performed). The parallel line tool was aligned with the outside of the white portion of the burst perimeter. Burst area was calculated along the inner edge of the burst opening following a Keyence scan. The fine edge portion of the external jaws of the calipers was used for caliper measurements because lining up the parallel lines of the fine external jaws was believed to be a more repeatable way to measure the burst opening than inserting the internal jaws, where (1) the thin material at the burst edge is thinned, so it is easier to deform, (2) the material at the burst edge is brittle, so it is prone to chipping, and (3) aligning the internal jaws so they are perpendicular to the burst is more difficult to achieve. Images that show the procedure for measuring burst length, width and area are provided below in Figure 3-7.
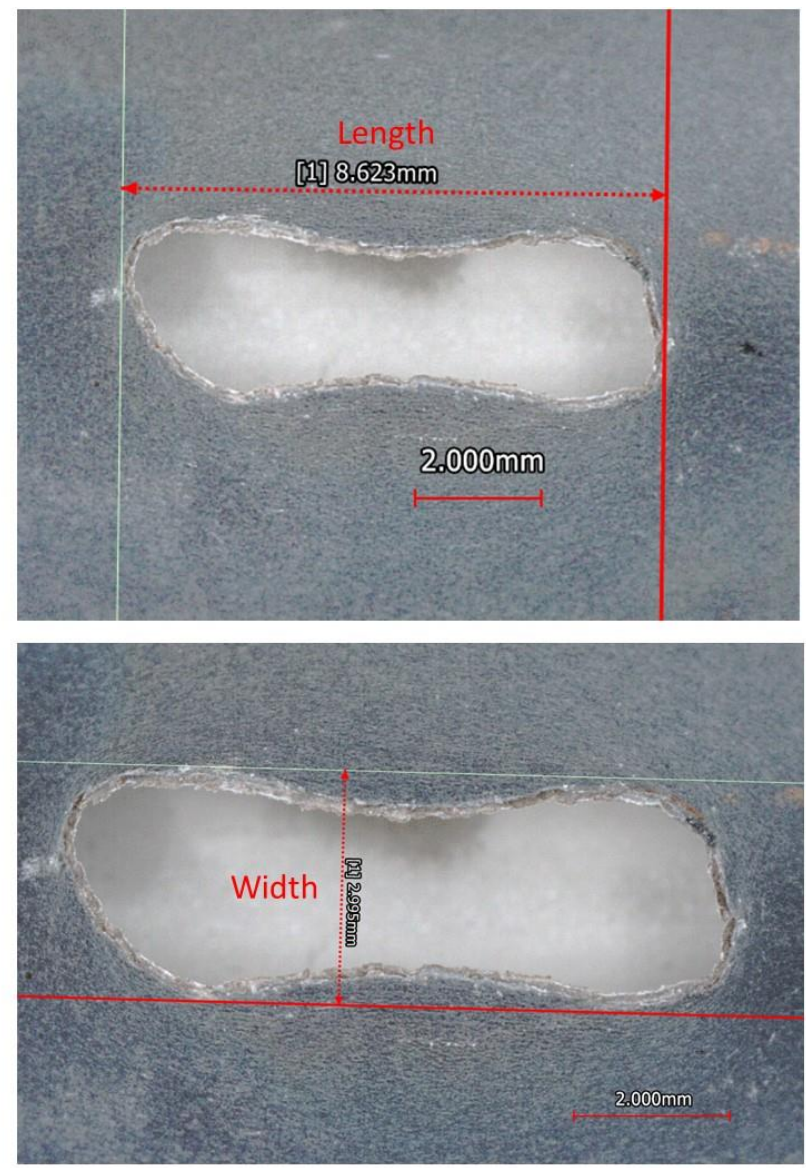

Figure 3-7 Showing how burst opening length (top) and opening width (bottom) are measured using the plane measurement, parallel line tool on the Keyence live image. Burst measurements were done in the same fashion with calipers where the edges of the external jaws followed the parallel lines shown above.

The relationship between measured burst opening length, burst opening width, and burst opening area vs. hoop stress is illustrated in Figure 3-8. In general, the results are expected to depend on other test parameters like gas volume, balloon size, the material's local crack propagation properties, and potentially internal pressure up to a certain pressure. More research is recommended to better understand the relationship between the burst opening and other test/specimen parameters. Although the current study reports on a limited sample size, there was no clear effect of the Cr coating on either improving or 
worsening the burst opening length/area. The results of the Keyence and caliper measurements are shown below in Table 3-1. The average difference between the burst opening length measured by caliper vs. Keyence was $0.12 \mathrm{~mm}$, and the average percent difference (calculated by dividing the length difference by the Keyence measurement) between them was $1.5 \%$, suggesting that both measurement methods are repeatable and comparable. The maximum percent difference was $6.1 \%$ for length, but that was for the specimen with the smallest burst opening, which makes it more difficult to measure with calipers. In general, since the burst opening is mostly important for fuel dispersion implications, measuring larger burst openings more accurately is more important. Similarly, the difference between the width measurement taken by caliper vs. Keyence was $0.07 \mathrm{~mm}$, and the average percent difference was $2.7 \%$. The larger trend in percent error is expected because the magnitudes of the measurements were smaller. The maximum error for burst opening width was $4.2 \%$.

Diametrical strain, which is an indication of total cladding ballooning, was measured along cladding length via image analysis using a Keyence-3000 and normalized to initial cladding diameter $(9.52 \pm .01$ $\mathrm{mm}$ ) and is reported for all burst claddings in Figure 3-9. By integrating diametrical strain along cladding length, total strain can be calculated in units of $\% \cdot \mathrm{cm}$. Strain integration is reported in Figure 3-10. At all internal overpressures where burst testing of both $\mathrm{Zr} 4$ and $\mathrm{Cr} / \mathrm{Zr} 4$ was performed, there was a marginal decrease in total strain for $\mathrm{Cr}$ coated $\mathrm{Zr} 4, \sim 4 \%$ decrease at $5.5 \mathrm{MPa}, \sim 4 \%$ decrease at $8.3 \mathrm{MPa}$, and $\sim 8 \%$ decrease at 9.6 $\mathrm{MPa}$. As there was no clear relationship between a Cr coating and decreased burst opening length/area (Figure 3-88), the calculated decreases in total strain may be a marker of improved ballooning behavior. Decreased ballooning may have implications for reducing release of fragmented fuel. However, replicate testing is necessary for statistical confirmation of the marginal strain decreases, and furthermore, in-situ methods of observing and calculating cladding strain leading up to and during burst.

Table 3-2. Burst measurements taken from micrometer and Keyence microscope (Measurements in mm unless otherwise stated)

\begin{tabular}{lccccccc}
\hline & & \multicolumn{3}{c}{ Micrometer measurements } & \multicolumn{2}{c}{ Keyence measurements } \\
\cline { 3 - 8 } Material & $\begin{array}{c}\text { Initial pressure } \\
\text { (MPa) }\end{array}$ & $\begin{array}{c}\text { Burst } \\
\text { opening } \\
\text { length }\end{array}$ & $\begin{array}{c}\text { Burst } \\
\text { opening } \\
\text { width }\end{array}$ & $\begin{array}{c}\text { Diametrical } \\
\text { strain at } \\
\text { burst }(\%)\end{array}$ & $\begin{array}{c}\text { Burst } \\
\text { opening } \\
\text { length }\end{array}$ & $\begin{array}{c}\text { Burst } \\
\text { opening } \\
\text { width }\end{array}$ & $\begin{array}{c}\text { Burst } \\
\text { opening } \\
\text { area }\left(\mathbf{m m}^{2}\right)\end{array}$ \\
\hline Bare Zry-4 & 5.5 & 9.23 & 2.17 & 20.7 & 9.18 & 2.20 & 12.18 \\
Bare Zry-4 & 8.3 & 10.40 & 2.78 & 30.7 & $*$ & $*$ & 23.84 \\
Bare Zry-4 & 9.6 & 8.57 & 2.87 & 33.5 & 8.62 & 2.99 & 17.90 \\
Cr/Zr4 & 4.1 & 5.63 & 1.47 & 24.2 & 5.31 & 1.44 & 4.08 \\
Cr/Zr4 & 5.5 & 9.79 & 2.64 & 10.2 & 9.62 & 2.73 & 16.67 \\
Cr/Zr4 & 8.3 & 9.97 & 2.68 & 42.5 & $*$ & $*$ & 19.81 \\
Cr/Zr4* & 9.6 & 8.41 & 2.54 & & 8.29 & 2.59 & 13.54 \\
Average difference between micrometer and Keyence: & & 0.12 & 0.07 & N/A \\
\hline Standard deviation of difference between micrometer and Keyence: & 0.13 & 0.04 & N/A \\
\hline Percent difference between average difference and average length: & $1.5 \%$ & $2.7 \%$ & N/A \\
\hline
\end{tabular}

* Specimen was sectioned for microscopy mount, so burst opening length and width were not measured on the Keyence. 
(a)

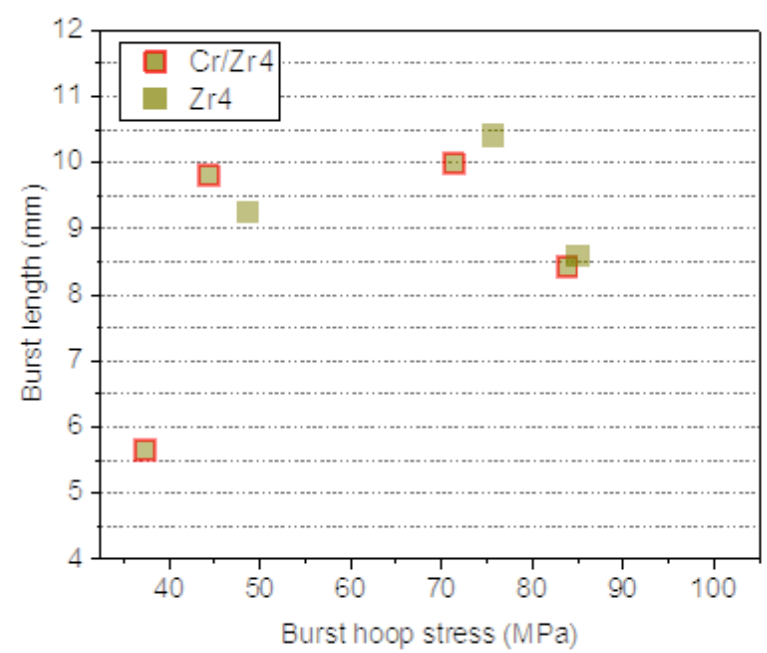

(b)

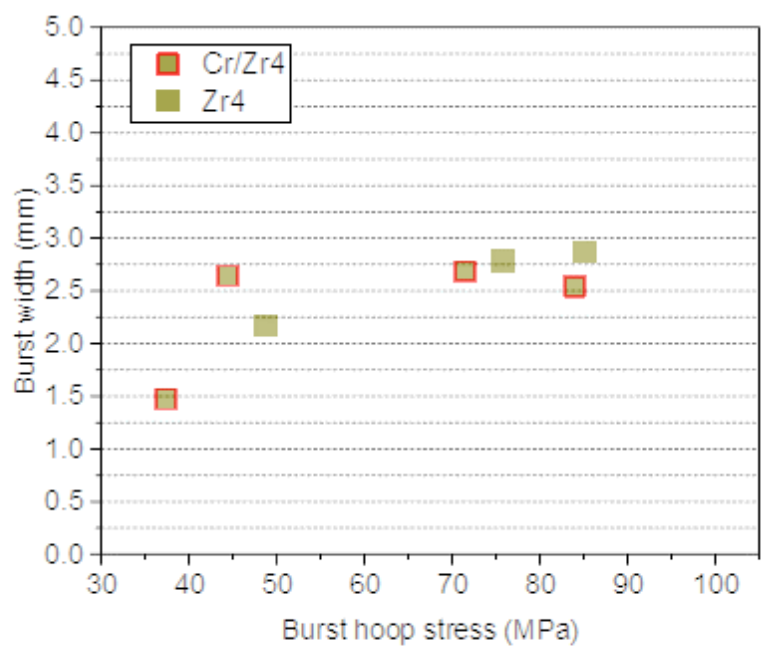

(c)

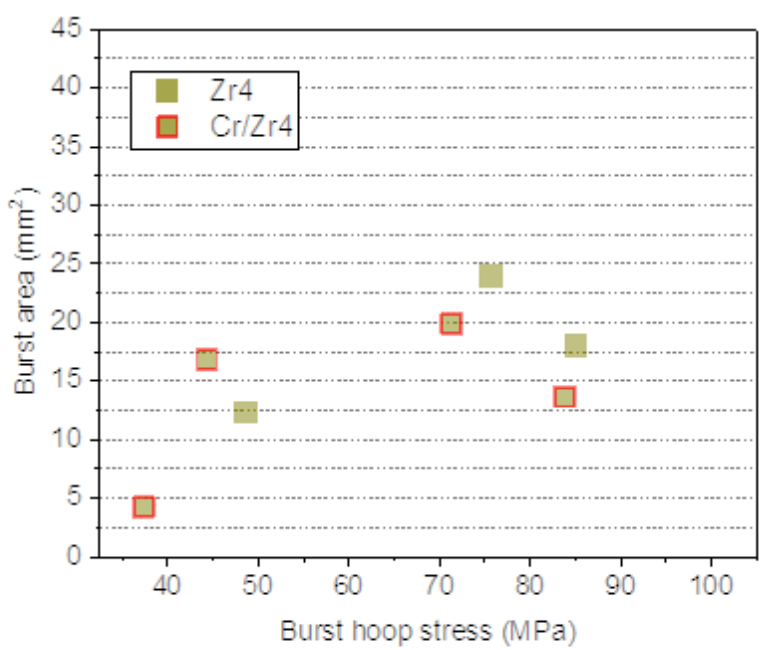

Figure 3-8. Relationship between (a) burst opening length, (b) burst opening width, (c) burst opening area and burst hoop stress for bare Zry-4 and Cr/Zr4. 

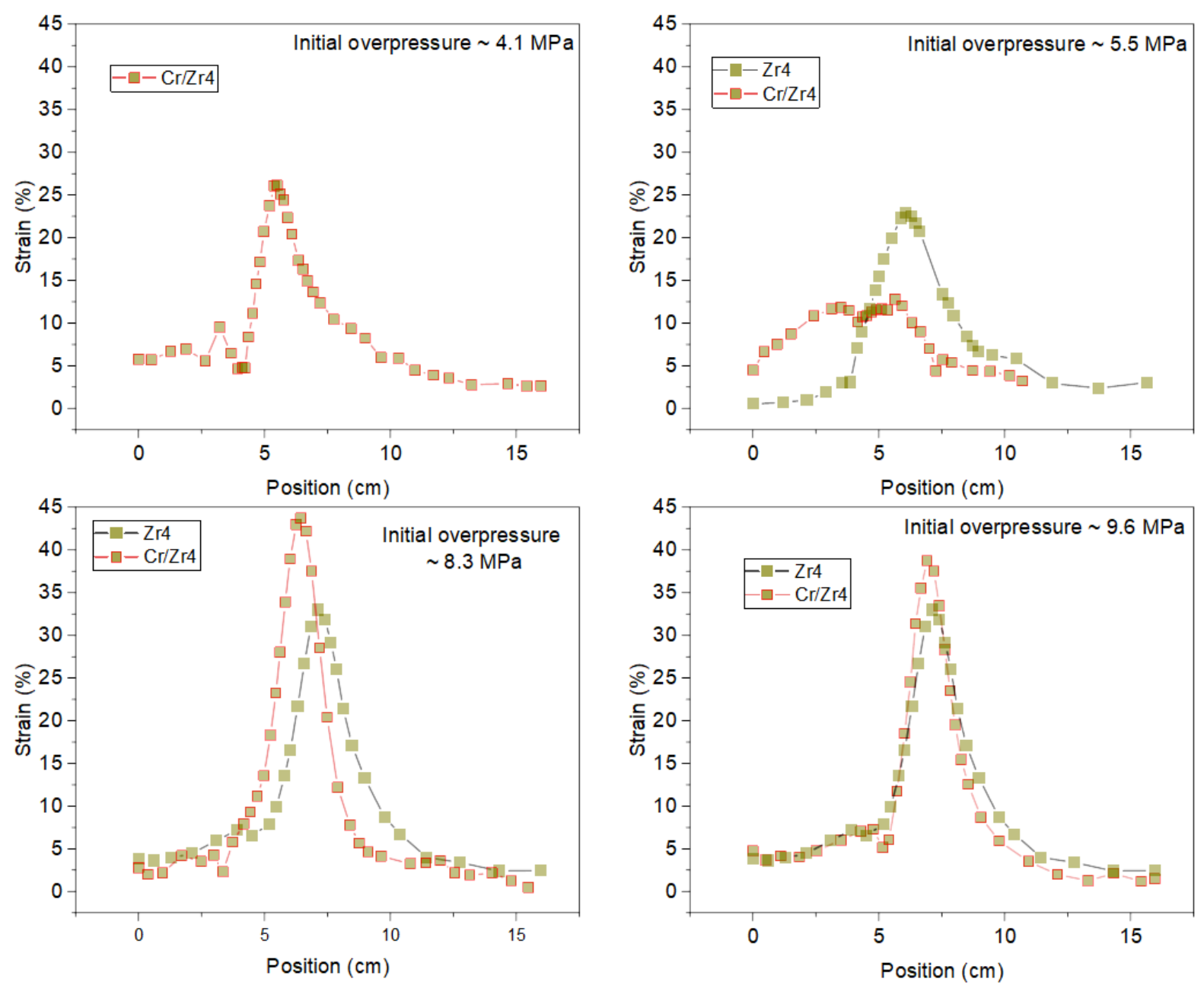

Figure 3-9. Diametrical strain of $\mathrm{Zr} 4$ and $\mathrm{Cr} / \mathrm{Zr} 4$ along the cladding length after burst testing. 


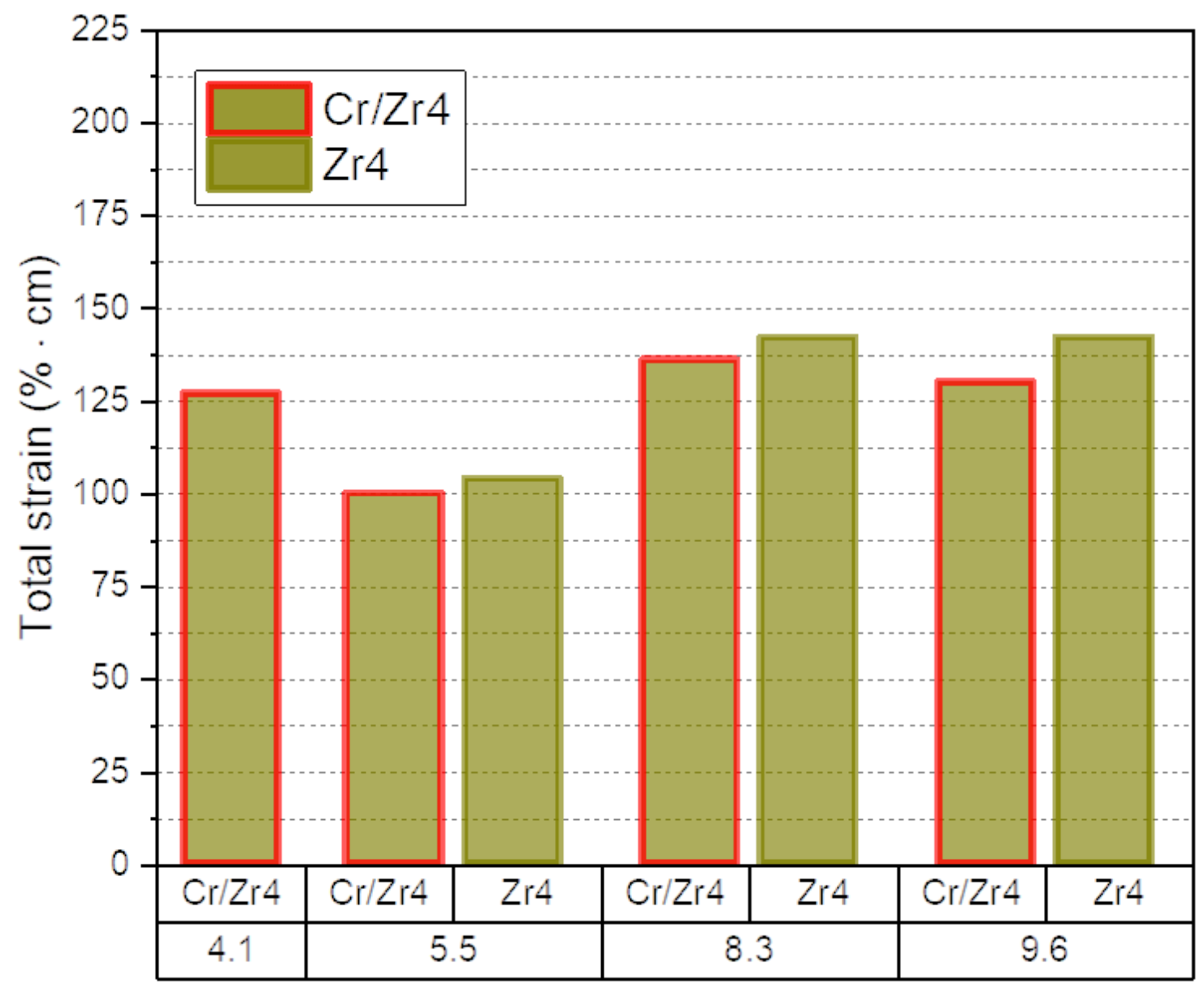

Figure 3-10. Total strain of claddings' bursts, post-calculated by integrating diametrical strain along cladding length.

\subsection{SCANNING ELECTRON MICROSCOPY}

The coated and uncoated specimens tested at $8.3 \mathrm{MPa}$ initial pressure were sectioned and prepared for SEM analysis. The center $\sim 100 \mathrm{~mm}(\sim 50 \mathrm{~mm}$ on either side of the burst) was cut, and then the specimen was cut down the center of the burst. A small ring (it was a ring before burst) was sectioned from one half to be mounted to view the cross section, and the other was left as-is to view the outer surface and burst perimeter.

Images showing the cross section of the uncoated and coated materials on the circumferential location furthest away from the burst tip where there was a thermocouple are shown in Figures 3-11a and 3-11b. For Figure 3-11, the coating (or oxidized coating), Zr-oxide, and alpha/prior-beta $\mathrm{Zr}$ layers are labeled. The thickness of the oxide layer was measured three times for each image, and the average was taken as the oxide layer thickness. For the coated specimen, the surface roughness persisted through oxidation, so three oxide thickness measurements were taken at the minimums (valleys) and maximums (plateaus), as shown in Figure 3-11b. Optical microscopy is recommended for measurement of the alpha-Zr layer because it provides better contrast between the alpha and beta layers [30]. To determine if the coating had no negative impact on oxidation performance, the oxide layer measurements must be normalized to temperature, because zirconium-based alloy oxidations rates are known to depend strongly on temperature [30]. To verify if the unirradiated coating provided any protection from oxidation during a 
LOCA, the oxide layer measurements were compared to calculated oxide thickness from the temperature history of the thermocouple closest to oxide-measured location using the Cathcart-Pawal (CP) [31] relation integrated over the entire temperature history. For the uncoated specimen, the burst occurred near a thermocouple, so the thermocouple located 180 degrees of circumferential rotation away was sufficient to measure temperature, and only one location of oxide measurements was sufficient. For the coated specimen, burst occurred $\sim 45$ degrees of circumferential rotation away from the front thermocouple, so oxide measurements were taken $-135,-45,45$, and 135 degrees away from the burst and compared to the temperature histories of the front and back thermocouples. The uncoated specimen was measured to have an oxide layer thickness of 52.20 microns, and the coated specimen was measured to have an oxide layer thickness of 60.83 microns in the valleys and 67.11 microns at the plateaus. The CPcalculated oxide layers for the uncoated and coated materials were 51.49, 59.62 and 60.15 microns, respectively. The oxide measurement for the uncoated Zry-4 material and the $\mathrm{CrZr} 4$ material in the valleys agreed well with the $\mathrm{CP}$ calculation, but the measured oxide layer of the $\mathrm{CrZr} 4$ material in the plateaus was $14 \%$ greater than the calculated thickness. More testing that more precisely controls and measures oxidation temperature like the procedure described in the article by Yan et al. [30] would be required to confirm the oxidation performance of the coated material. Since no protection was expected from the coating, it is suspected that significant oxygen transport would occur, resulting in double-sided oxidation of the chromium coating (one side being the steam, and the other side being at the $\mathrm{Coat} / \mathrm{ZrO}{ }_{2}$ boundary). As a result, it is expected that the entire coating may have formed into chromia, but more analysis, such as higher magnification SEM and EDS, would be required to confirm whether any of the unoxidized coating remained.

(a)

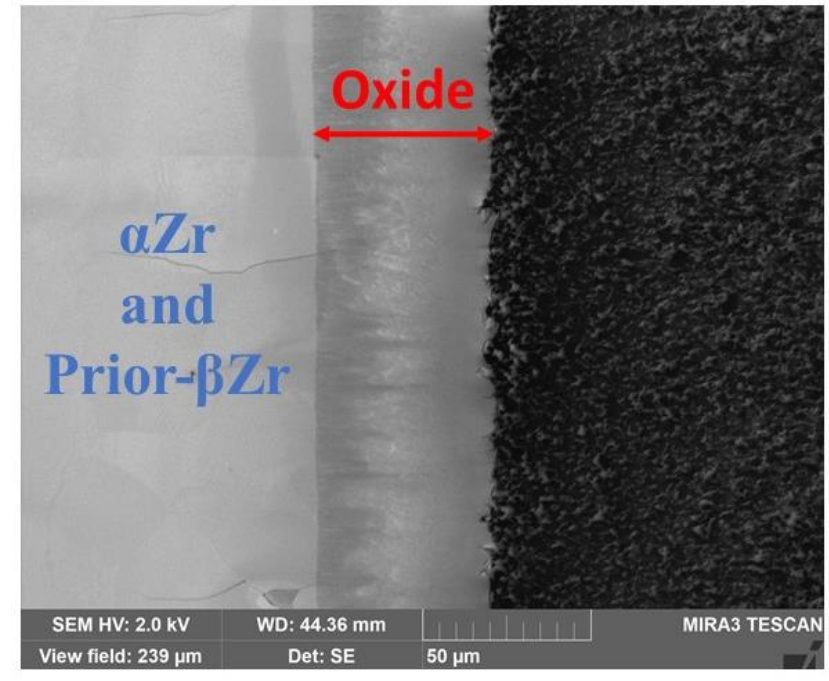

(b)

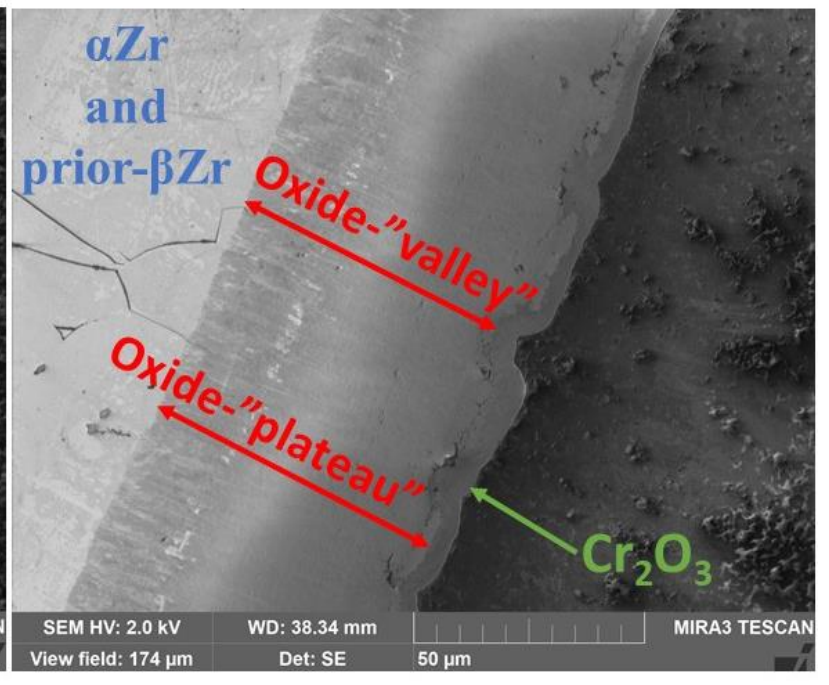

Figure 3-11. SEM images of the (a) uncoated Zry-4 180 degrees of circumferential rotation away from the burst near a thermocouple and (b) $\mathrm{Cr} / \mathrm{Zr} 4$ material at 135 degrees of circumferential rotation away from the burst near a thermocouple.

Images showing the cross section of the OD burst tip and OD surface of the $\mathrm{CrZr} 4$ material in the ballooned region near the burst tip are provided in Figure 3-12a and 3-12b, respectively. From the images, it is clear that there were large gaps in the chromium coating which exposed uncoated Zry-4 underneath. With the current coating, it is unclear if the numerous gaps were caused by a ductility mismatch at the $\mathrm{Cr}$ and Zry-4 interface or if those gaps are from cracks that were in the coating in the AR condition that translated along the circumference of the Zry-4 boundary as the Zry-4 deformed. More testing with a more uniform, uncracked coating is recommended to determine if the ductility mismatch would still cause coating cracks at high strains and thus leave the uncoated cladding unprotected. 
(a)

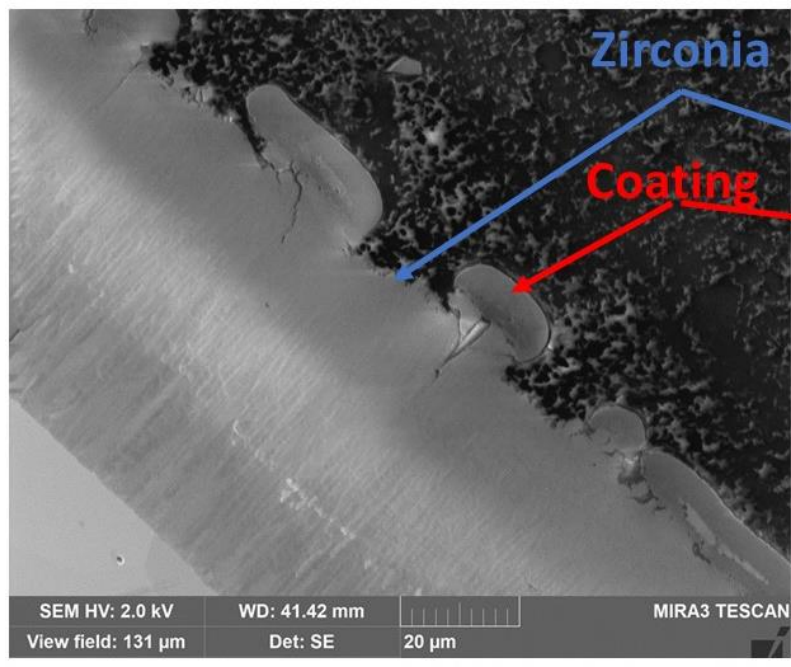

(b)

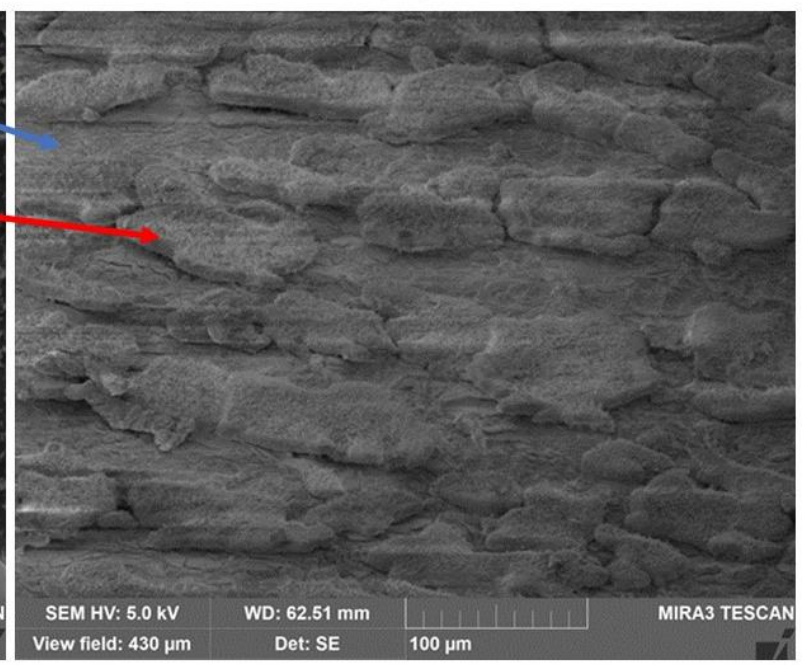

Figure 3-12. SEM images of (a) the cross section and (b) the outside surface of the coating at a high strain location near the burst tip showing significant gaps in the coating and exposure of the substrate $\mathrm{Zr}$ material.

\section{MODIFIED BURST TEST}

\subsection{EXPERIMENT DESIGN}

The MBT system at ORNL is a pulse-controlled mechanical testing technique that is used to determine the failure hoop strain of nuclear cladding tubes under light-water reactor (LWR) hot zero power (HZP) RIA conditions. This test was first developed and validated by the Electric Power Research Institute [16, 18], and it has been implemented and developed further at ORNL [5, 10, 11, 17]. The objective of the MBT setup is to simulate the PCMI phase of an RIA by imposing a plane strain loading condition on a cladding specimen at HZP temperatures $\left(\sim 275^{\circ} \mathrm{C}\right)$ and at the relatively high strain rates $\left(1\right.$ to $\left.5 \mathrm{~s}^{-1}\right)$ expected from those events [12]. Because the PCMI is produced by the expanding fuel, the loading is limited by the magnitude of fuel expansion, which means that the cladding must be tested up to the strains imposed by the fuel instead of a stress-based limit. Therefore, the strain on the cladding tube is measured to determine the strain (which correlates to the fuel expansion limit) that the cladding can withstand before failure under the PCMI loading condition.

A schematic of the MBT setup and an image of the system with components labeled are shown in Figure 4-1. The system consists of a 1-inch cladding specimen that is attached to an Inconel driver tube with Aremco Ceramabond 671. The driver tube includes a thin-walled region near the axial center to contain the strains near the center of the specimen. After the specimen was attached to the driver tube, its outer surface was spray painted with a speckle pattern using Rust-Oleum high-temperature enamel paint so that the images for DIC strain measurements could be taken using a high-frame-rate camera during the test. After the surface was painted, the driver tube was connected to a high-pressure line fitted with a pressure intensifier filled with nonflammable oil and pre-pressurized to $\sim 3 \mathrm{kpsi}$. After the specimen was connected, four lights and the six first-surface mirrors were aligned to project four opposite sides of the centralized cladding specimen so that the entire outer surface could be viewed simultaneously during the test. The projections were viewed through a telecentric lens with a focus depth of $15.8 \mathrm{~mm}$ so that all four orthogonal projections of the specimen at both working distances remained in focus. The event was recorded using a high-frame-rate camera. Once the four projections were visible and in focus, the stage was covered with a quartz box to insulate the test and to protect the user and lens from debris and oil upon 
burst; then the specimen was brought to temperature using four ceramic heaters. A thermocouple was attached to the bottom of the specimen by spreading the thermocouple wires into a loop, inverting the bead so that it faced inside the loop, placing the loop over the specimen, and pulling into contact with the specimen's outer surface to control the specimen temperature with the ceramic heaters. Once the setup was brought to $275^{\circ} \mathrm{C}$ and $\sim 30$ minutes had passed to allow the system to reach thermal equilibrium, the actuator moved at a constant velocity $(10.2 \mathrm{~mm}$ were given for the actuator to accelerate to velocity) toward the pressure intensifier or piston until it came into contact and began to rapidly compress the volume, which, in turn, quickly increased the pressure. This internal pressure induced a load on the Inconel driver tube, which then expanded, consequently expanding the cladding specimen.

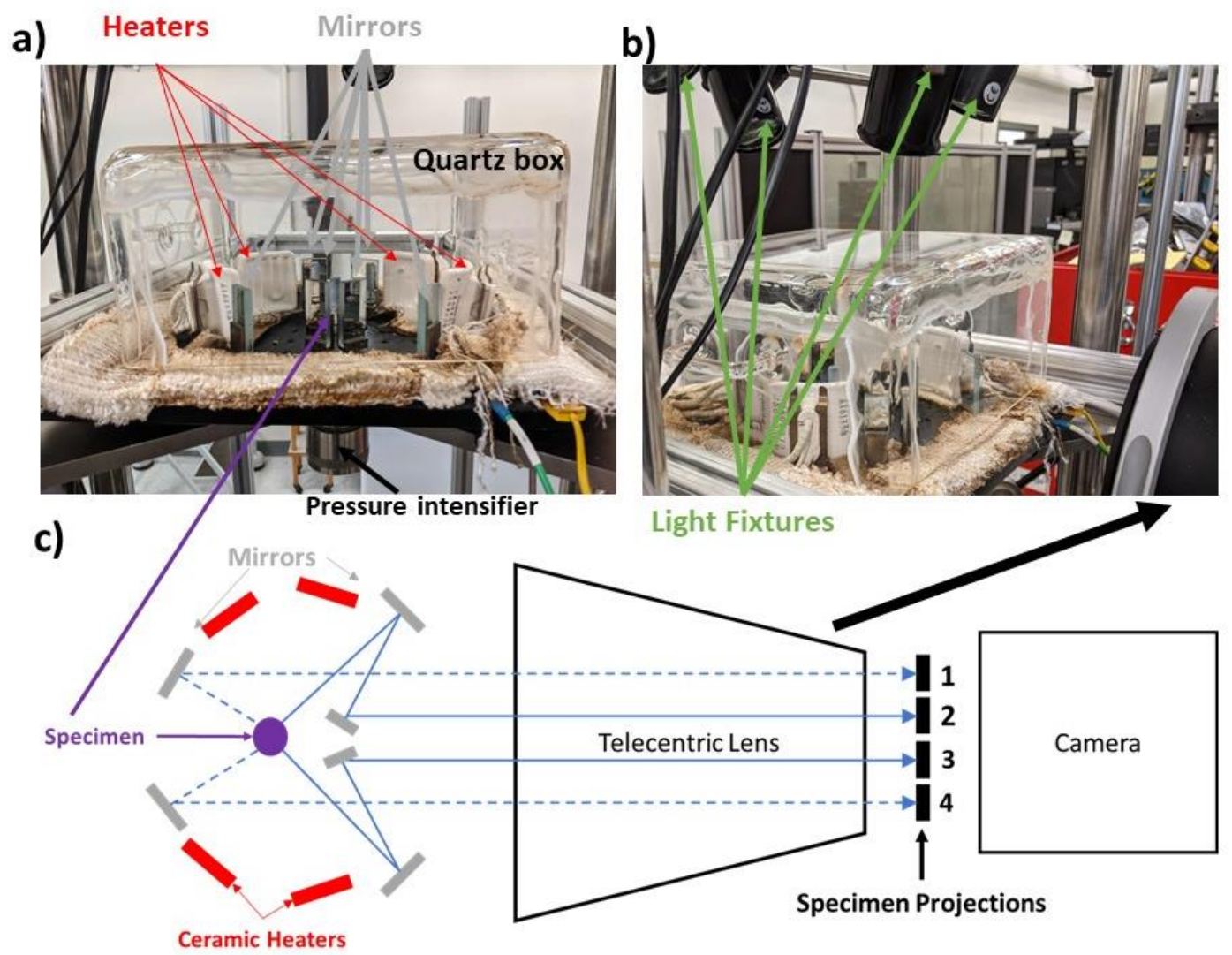

Figure 4-1. The modified burst test setup (a) and (b), and in schematic form (c), with crucial components labeled

The strain rate, which correlates to the pressurization rate, was modified by the rate of volume reduction in the pressure intensifier, which correlated to the controlled displacement rate of the actuator. MBTs in this work were performed on the uncoated and coated Zry-4 material at either $25.4 \mathrm{~mm} / \mathrm{s}$ or $76.2 \mathrm{~mm} / \mathrm{s}$ displacement rates, because those displacement rates were expected to produce strain rates within the PCMI strain rate range. Figure 4-2 shows the pressures produced by the actuator for this system. Pressurization rates are calculated from the initial part of the load, which is what is induced by the actuator. The slower rate portion after the first $\sim 60 \mathrm{~ms}$ was due to the frame returning from its deflection. Note that if the tube bursts, then the slow-rate pressures seen at the end of the pressurization do not occur. For tests performed at $10 \mathrm{in} . / \mathrm{s}$, the camera frame rate was 2,000 frames per second, and for tests performed at $30 \mathrm{in./s,} \mathrm{the} \mathrm{frame} \mathrm{rate} \mathrm{was} \mathrm{5,000} \mathrm{frames} \mathrm{per} \mathrm{second.}$ 


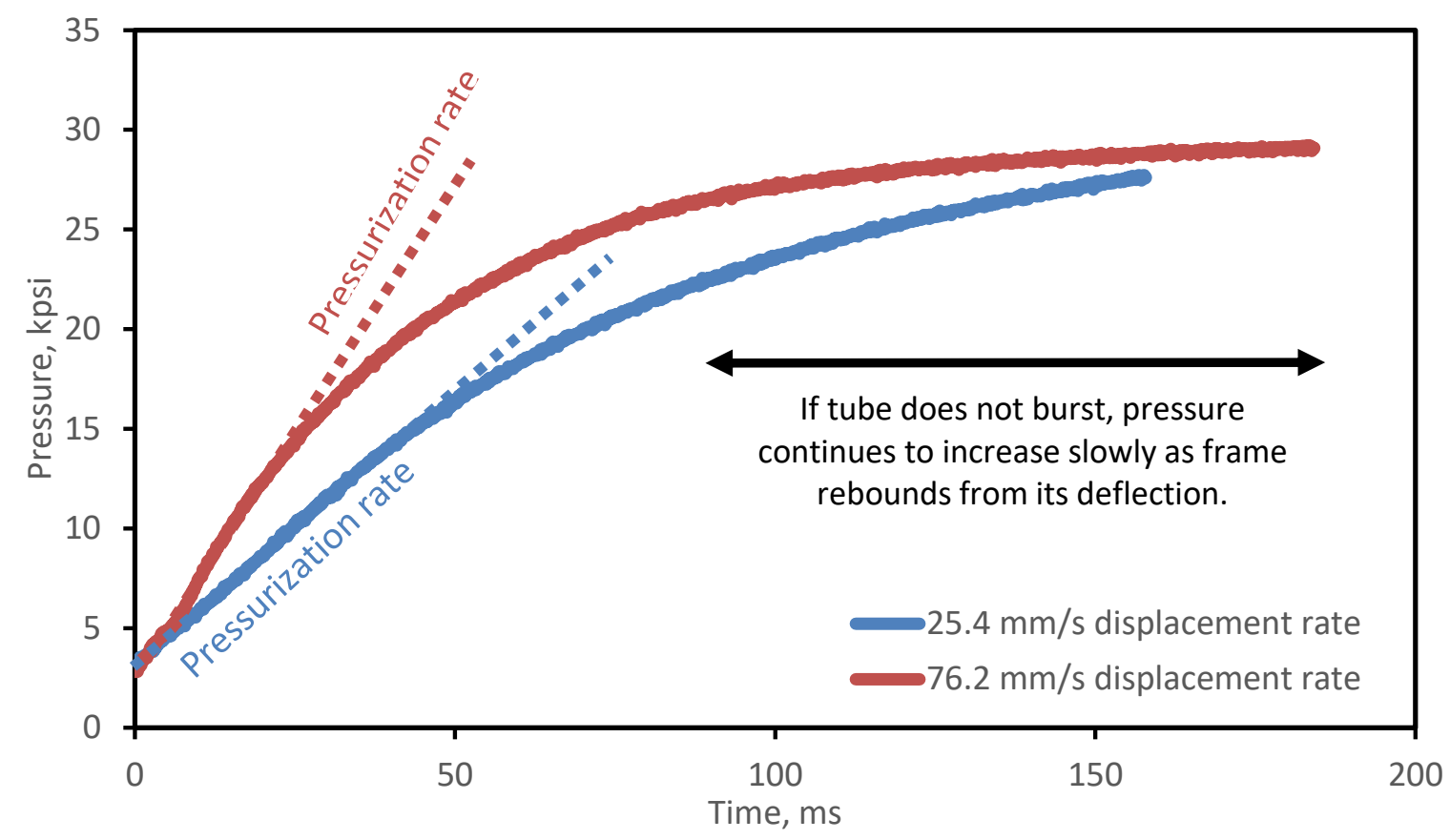

Figure 4-2. Pressures produced from the actuator displacement rates used in this work. Note that the slower pressurization rate at the end is not critical to the test, as it was caused by the plate recovering from its deflection.

Figure 4-3 shows select frames from the typical DIC output of the MBT using frames from the roomtemperature test of uncoated Zry-4 at $25.4 \mathrm{~mm} / \mathrm{s}$ displacement rate. Specifically, Figure 4-2a shows the $\sim 0$ strain reference image before the test start. The figure shows all that four projections (see Figure 4-1c) are well lit and in focus. Figure 4-2b shows the specimen after loading has begun; the projections are seen to move upward due to deflection of the frame from the actuator's impact. Even at this stage, no obvious ballooning can be seen. Finally, Figure 4-2c shows the specimen at the end of the test, after significant ballooning has occurred. 

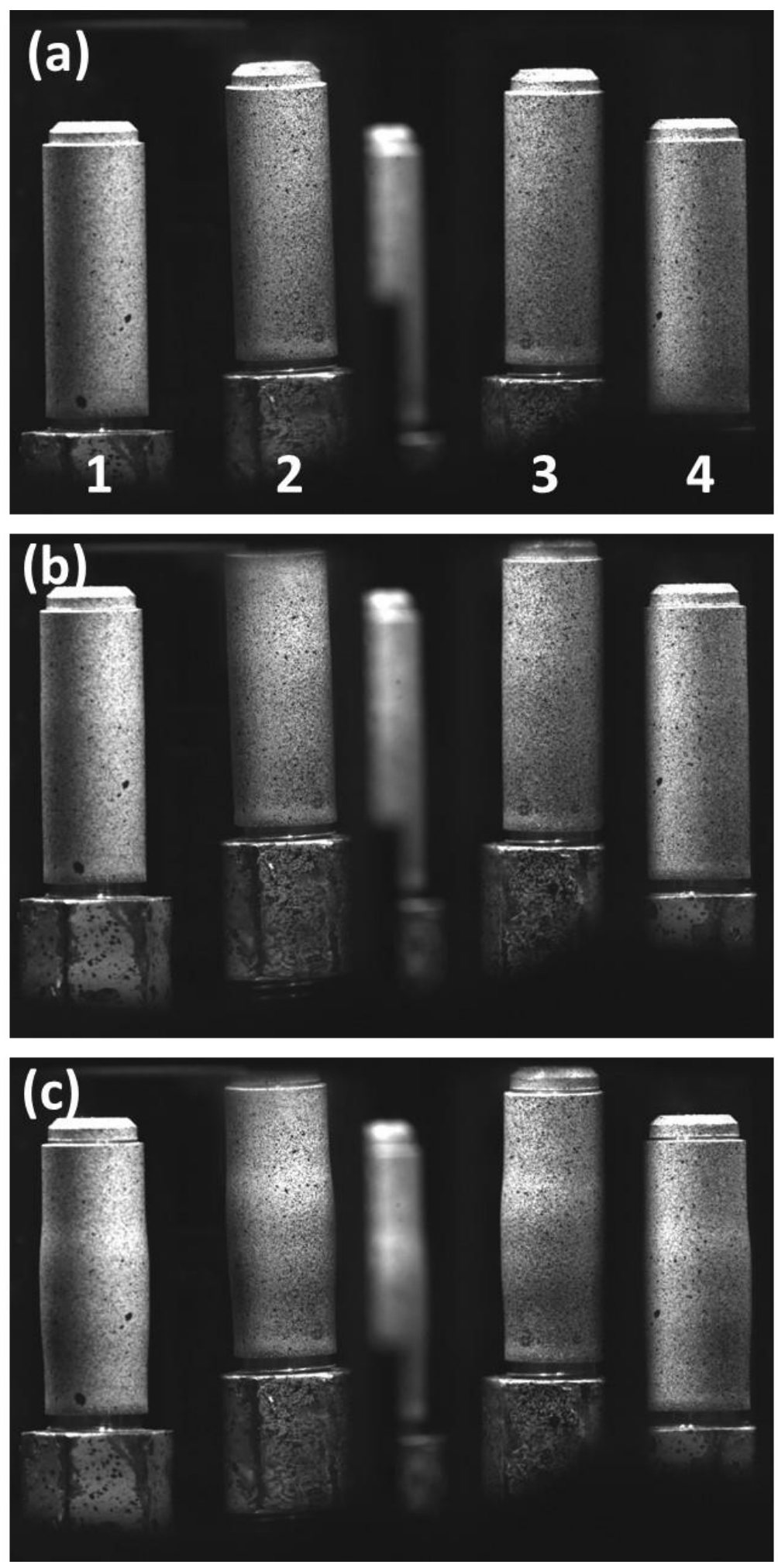

Figure 4-3. Images taken of all four projections around $360^{\circ}$ of the MBT specimen circumference are well lit and in focus: (a) reference image from the start of the test (b) from after the piston was hit and the frame deflected upward form the force ( $\sim 0$ strain on specimen), and (c) from the end of the test, where significant strain and ballooning are obvious. 


\subsection{RESULTS AND ANALYSIS}

2D DIC analysis was performed using Matlab to calculate strains from open-source DIC algorithms, Ncorr [19]. Figure 4-4 shows the process of DIC calculation for the room temperature test of uncoated Zry-4 performed at $10 \mathrm{in./s} \mathrm{displacement} \mathrm{rate.} \mathrm{In} \mathrm{Figure} \mathrm{4-4a,} \mathrm{a} \mathrm{field} \mathrm{object} \mathrm{with} \mathrm{a} \mathrm{subset} \mathrm{size} \mathrm{of} 47$ pixels and a step size of 10 pixels was created along the center of each specimen projection, producing a $\sim 10 \times$ 25 grid of nodes. For reference, the OD of the tube for each projection was $\sim 150$ pixels. Since a telecentric lens produces the orthogonal projection of the specimen, there is no parallax error between the two projection distances or from the tube ballooning toward the lens as long as they all remain within the focus depth of the lens. Nodal strain outputs were taken along the center of each field because the error due to performing 2D DIC on the curved surface is minimized when looking perpendicular to the surface. Specifically, the error was measured to be $<0.025 \%$ strain at the centerline and $<0.05 \%$ strain for 47 -pixel nodes for $1 / 2$ the tube radius ( 40 pixels away in this case) from the centerline [11]. After they were created, the objects were traced through to the end of the test. Figure 4-4b shows the calculated first principal strains (should be equivalent to the hoop strains), and Figure 4-4c shows the calculated second principal strains (should be equivalent to axial strains). From these field calculations, it was observed that the gauge section of the specimen, which was over the thin-walled region of the driver tube, was under high tensile strain, and it appeared to be mostly uniform (with no highly localized strain or discontinuity). Outside of the gage section, there was near zero hoop strain. Axial strains in the gauge section were also observed to be uniform. Furthermore, it was noted that the edges of the gauge section (highlighted in Figure 4-4c) had about 3\% compressive strain. This is postulated to be because the specimen was pinned into the corner of the driver tube where the ballooning region transitioned to the unstrained region. This is shown schematically in Figure 4-5. 

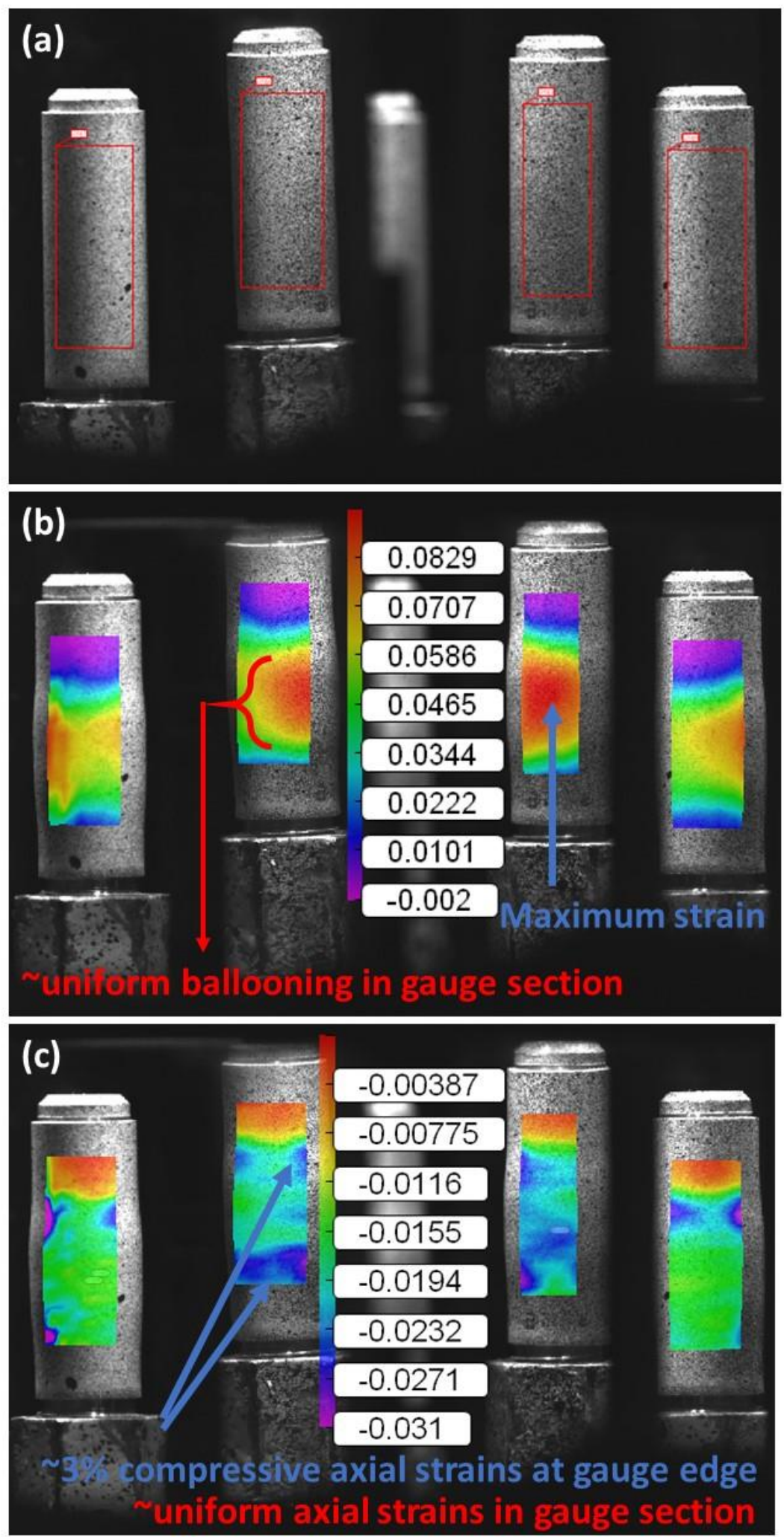

Figure 4-4. Strain calculation procedure: (a) showing where the fields were placed for DIC calculation on the reference image (b) the first principal strains showing where the maximum strain location was found, and (c) the second principal strains showing compressive bands near where the ballooning began. 


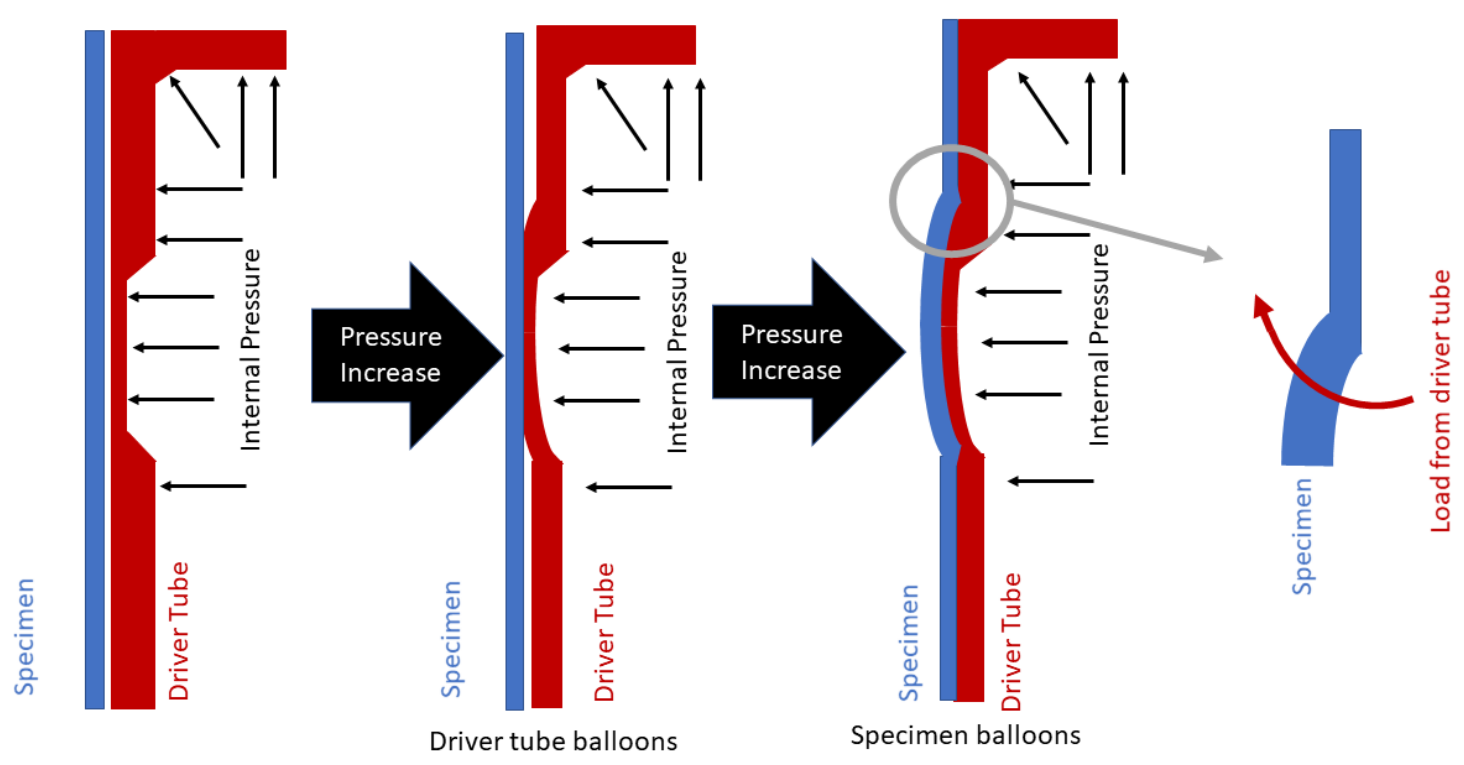

Figure 4-5. Schematic showing the postulated cause of the compression band near where the ballooning region begins. As the driver tube expands outward, the specimen gets pinned in the corner and is compressed.

From the strain fields generated for each test, the node at the maximum strain location (highlighted in Figure 4-4b) was output to calculate maximum hoop strain during the high strain rate portion of the test, strain biaxiality, and strain rate. The strain calculated at the maximum strain at the high strain rate location on the uncoated specimen performed at room temperature and $25.4 \mathrm{~mm} / \mathrm{s}$ displacement rate are shown in Figure 4-6. Because the specimen did not burst, the specimen had a slower increase in strain due to the fixture relaxation. Furthermore, without the burst, strains did not accelerate near the end of the high strain rate portion of the test as seen before [10]. Therefore, since the strain rates appeared to be linear, for this work, the strain rate was calculated during the high strain rate portion (see Figure 4-6) of the test by plotting the strains with time and using a best fit linear curve. Since strain rate is known to effect ductility, the maximum strain achieved at the high strain rate and the absolute maximum strain were reported. Furthermore, it was observed that the hoop strain was close to the first principal strain, and the axial strain was close to the second principal strain, showing that the mechanical behavior test results are applicable to the cylindrical coordinate system used for tubes. Strain biaxialities are calculated by dividing the second principal strain by the first principal strain. 


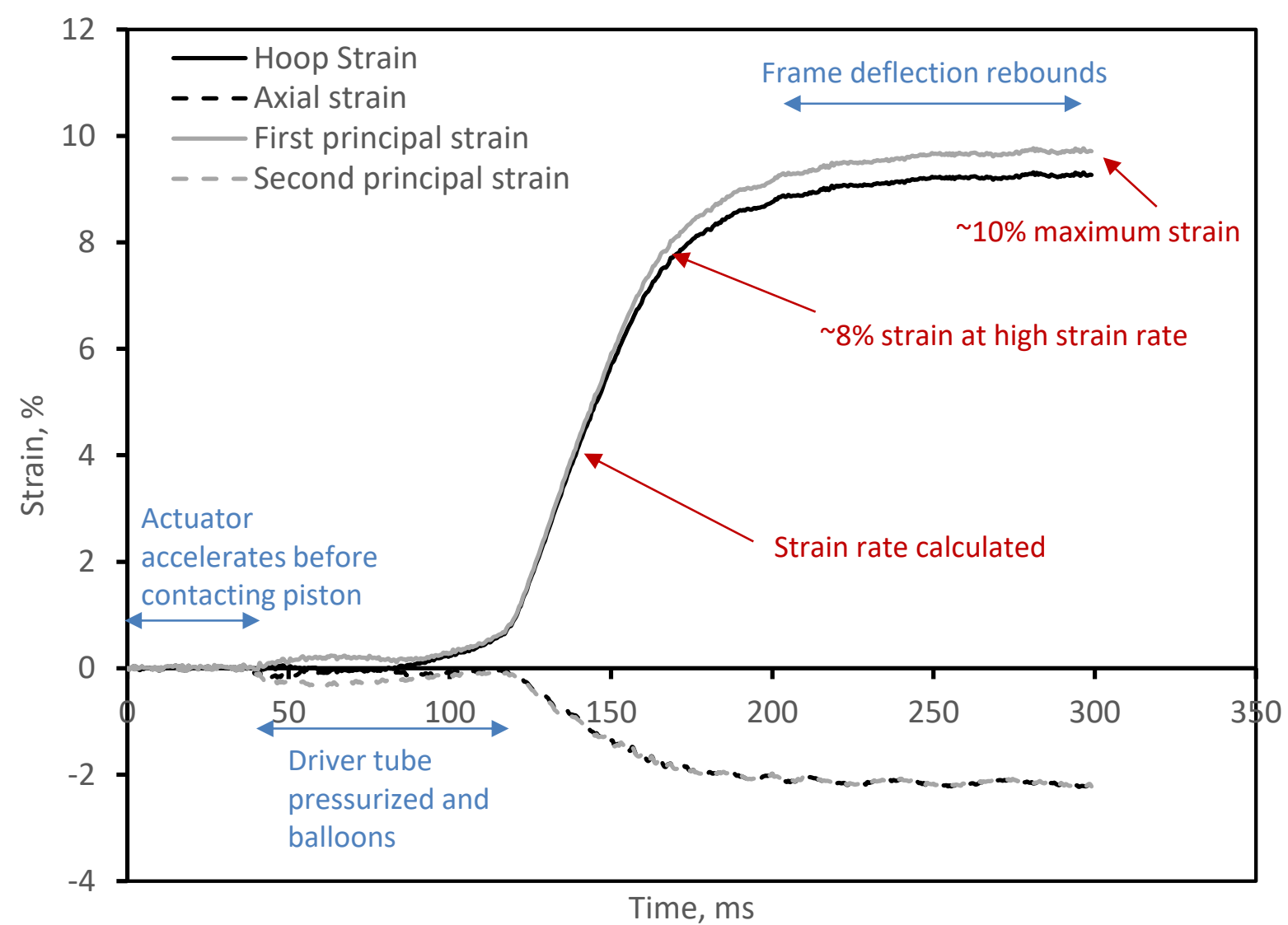

Figure 4-6. DIC strain calculation for the Zry-4 specimen tested at room temperature and at $25.4 \mathrm{~mm} / \mathrm{s}$ actuator displacement rate showing how maximum strains and strain rate were calculated.

The test parameters, maximum pressures, strain rates, strains reached at high strain rate, maximum strains, and strain biaxialities are shown below in Table 4-1. The strain rates achieved in this work were well in the range of PCMI expectations $\left(1-5 \mathrm{~s}^{-1}\right)$ [12]. It was found that the strain rates at room temperature were slower than those at high temperature. The cause for this is currently unknown. With the exception of CrZr4_4, which appeared to be an outlier test, all specimens were found to withstand hoop strain greater than $4.5 \%$ under high strain rate MBT conditions, and the coating did not appear to have any effect on MBT strain. CrZr4_4 did not burst below that strain, but it only underwent 1.6\% strain at its fastest strain rate. Moreover, the coating in the ballooned region appeared to remain intact during the short time that strain images were taken. Strain biaxialities achieved during testing were close to plane strain conditions for Zry-4_5, CrZr4_2, and CrZr4_5, but the other three tests calculated significantly large negative biaxialities. Considering that Zry-4_5 and CrZr4_5 were both conducted at room temperature and the higher rate test (both expected to cause loss of ductility), it looks promising that the slower rate or higher temperature tests would remain unburst, even if they were under plane strain conditions. 
Table 4-1. MBT test matrix and principal strain calculations

\begin{tabular}{|l|l|l|l|l|l|l|l|l|l|l|l|}
\hline Material & Temp & Rate & $\begin{array}{l}\text { Max } \\
\text { pressure }\end{array}$ & Burst? & $\begin{array}{l}\text { strain } \\
\text { rate }\end{array}$ & e1 fast & e2 fast & biax fast & $\begin{array}{l}\text { e1 } \\
\text { max }\end{array}$ & $\begin{array}{l}\text { e2 @ } \\
\text { e1 max }\end{array}$ & $\begin{array}{l}\text { biax at } \\
\text { max }\end{array}$ \\
\hline & C & in/s & kpsi & & s-1 & $\%$ & $\%$ & N/A & $\%$ & $\%$ & N/A \\
\hline Zry-4_4 & RT & 10 & 26.60 & No & 1.6 & 7.6 & -1.9 & -0.25 & 9.7 & -2.3 & -0.24 \\
\hline Zry-4_5 & RT & 30 & 28.40 & No & 3.0 & 6.6 & 0.15 & 0.02 & 9.6 & 0.08 & 0.01 \\
\hline Zry-4_2 & 275 & 30 & 22.00 & No & 5.3 & 6.1 & -1.1 & -0.18 & 8.2 & -1.2 & -0.15 \\
\hline CrZr4_4 & RT & 10 & 27.70 & No & 0.2 & 1.6 & 0.21 & 0.13 & 2.20 & 0.23 & 0.10 \\
\hline CrZr4_5 & RT & 30 & 29.20 & No & 3.5 & 4.6 & -0.37 & -0.08 & 10.1 & -0.67 & -0.07 \\
\hline CrZr4_2 & 275 & 30 & 21.00 & No & 5.0 & 6.2 & 0.29 & 0.05 & 8.0 & 0.47 & 0.06 \\
\hline
\end{tabular}

Zry-4 ductility is known to depend on the state of strain and stress [12, 14, 16], and the PCMI loading condition is postulated to be at the plane strain condition [12]. Therefore, the performance of the cladding at those loading conditions should be measured. To that end, the strain fields for each specimen in which the maximum strains were not under near plane strain were analyzed to determine the maximum plane strain hoop strain. To accomplish this, the second principal strain ( axial strain) fields were analyzed, starting on the image at the end of the high strain rate portion of the test, and stepping through the images backwards, chronologically, until a node with zero or a small positive axial strain could be found. It should be noted that small positive strains are expected to be a conservative estimate of the plane strain condition because ductility under biaxial tension states is expected to be lower than that of plane strain $[12,15]$. Table 4-2 shows the maximum strains near the plane strain condition for each test. These data show that a plane strain condition was successfully induced in all but one MBT specimen. Moreover, it is worth noting that the one specimen that did not experience plane strain (Zry-4_4) and the specimen that did not undergo a high magnitude of strain $(\mathrm{CrZr} 4$ _4) were of the lower strain rates, which would be expected to be more ductile than higher strain rate counterparts [16].

Table 4-2. Maximum first principal ( hoop) strains near the plane strain loading condition during the high strain rate portion of each test

\begin{tabular}{lccccccc}
\hline Material & Temp & Rate & $\begin{array}{c}\text { Max } \\
\text { pressure }\end{array}$ & Burst? & $\begin{array}{c}\text { Max plane } \\
\text { strain e1 }\end{array}$ & $\begin{array}{c}\text { e2 at plane } \\
\text { strain }\end{array}$ & biaxiality \\
\hline & C & in/s & Kpsi & & $\%$ & $\%$ & unitless \\
Zry-4_4 & RT & 10 & 26.60 & No & N/A & N/A & N/A \\
Zry-4_5 & RT & 30 & 28.40 & No & 6.6 & 0.15 & 0.02 \\
Zry-4_2 & 275 & 30 & 22.00 & No & 3.2 & 0.08 & 0.03 \\
CrZr4_4 & RT & 10 & 27.70 & No & 1.6 & 0.21 & 0.13 \\
CrZr4_5 & RT & 30 & 29.20 & No & 4.2 & 0.27 & 0.06 \\
CrZr4_2 & 275 & 30 & 21.00 & No & 6.2 & 0.29 & 0.05 \\
\hline
\end{tabular}

It was observed that the coating cracked during MBT along the compressive strain band around the circumference of the specimen for the coated materials. From the nodal strain output at the location where this coating crack initiated, the DIC strain was calculated to be about $-1.5 \%$ strain when the crack initiated. This is shown below in Figure 4-7, where 4-7a shows the crack around the tube circumference for the test performed with $\mathrm{CrZr} 4$ at room temperature for $30 \mathrm{in} . / \mathrm{s}$ displacement rate. This behavior is not expected to preclude the coated tube safety under the PCMI test because the cladding itself did not burst. More testing is required to further understand this result. Furthermore, an image of the CrZr4 specimen tested at $275^{\circ} \mathrm{C}$ after the specimen was cooled is shown in Figure 4-7b. During the test, the only visible 
coating damage was similar to that shown in 4-7a, but after cooling to room temperature, the coating damage evolved further into what is shown in Figure 4-7b. Because this circumferential cracking and peeling did not occur on the uncoated material or from results with uncoated FeCrAl [10], it is expected to be from the coating itself. This result shows that the coating adhered better to the spray paint than the substrate Zry-4, which further supports careful control during the coating process, such as substrate surface quality and HiPIMS parameter optimization, to provide better adherence of the chromium coatings to the cladding.

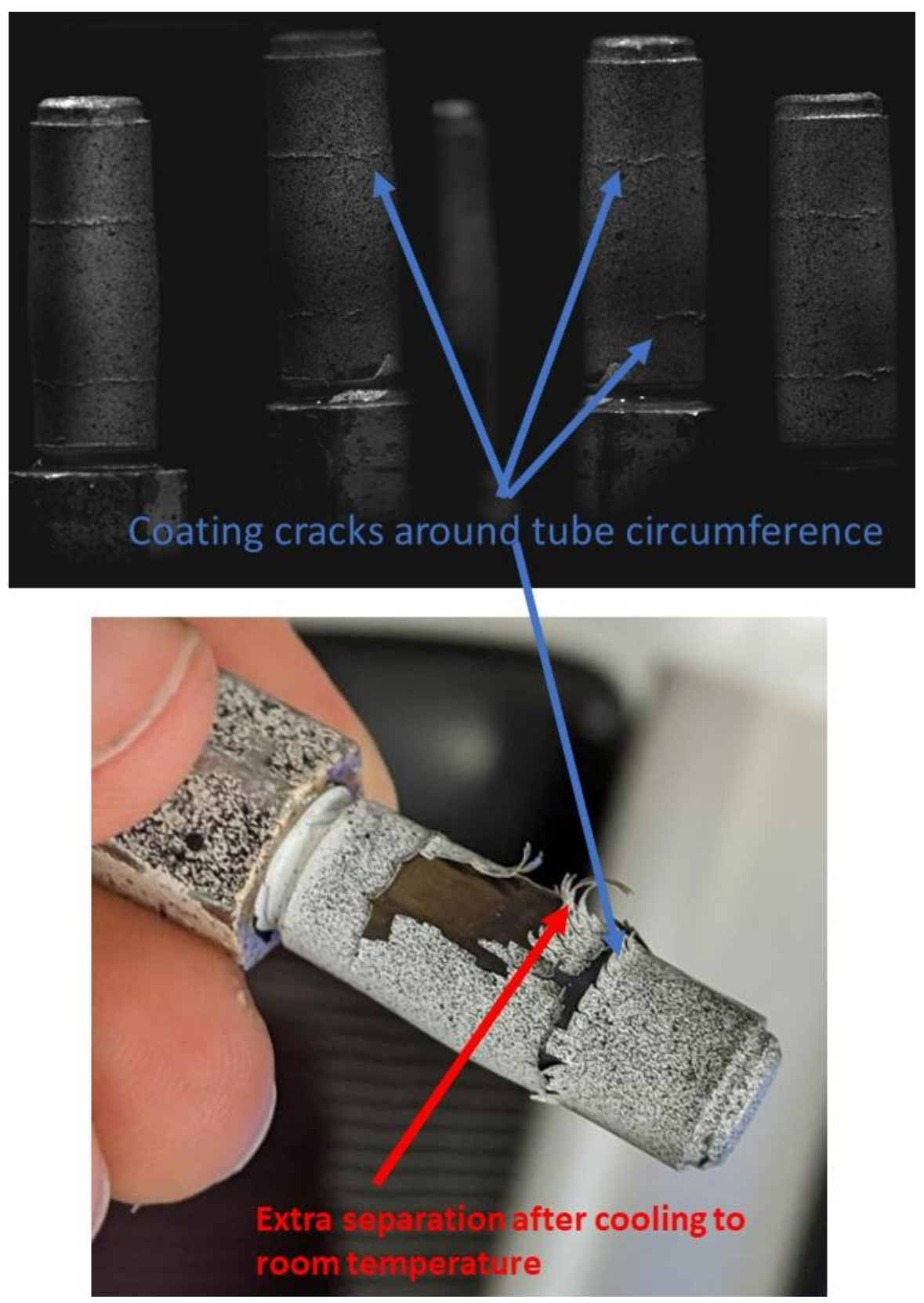

Figure 4-7. MBT results with CrZr4 showing the crack around the tube circumference near the edge of the balloon region, which occurred at all temperatures (top), and further separation of the coating from the cladding after the specimen cooled from $275^{\circ} \mathrm{C}$ to room temperature (bottom). No crack was present for any uncoated specimen. 


\section{CONCLUSIONS AND FUTURE WORK}

Zry-4 cladding tubes were purchased under ASTM B353-12 to be coated with a 7-micron layer. The coating layer was measured to be 4.75 microns thick. The tubes were found to have an unacceptable surface finish with visible scratches on the surface, and further investigation of the coated tubes showed visible signs of coating damage in the AR condition. If the coated cladding is to be used in a reactor, then it must be tested under accident conditions to verify that it performs as good or better than its uncoated counterpart. To that end, this material was tested under design-basis LOCA conditions and RIA PCMI conditions at ORNL, where the following was concluded:

- The coated cladding did not appear to have any effect on the burst temperature, pressure, or burst measurements from LOCA testing. It did appear to slightly lower the total diametral strain, but only 3 tests were performed, and the difference was marginal. More tests are required to conclude that there is a repeatable difference in total strain.

- Post-LOCA SEM images revealed that the coating gave no protection from oxidation under the hightemperature steam environment of the SATS system. This is likely due to the cracks and divots that were apparent in the coating in the as-received condition or from additional cracks that were formed during the LOCA. Moreover, SEM images revealed that there is a significant ductility mismatch between the chromium coating and Zry-4 substrate, such that the coating completely separated into pieces from the high-strain ballooning during the LOCA burst tests.

- Zry-4 cladding did not burst under PCMI strain rates and strain states, and except for one test, the $\mathrm{CrZr} 4$ material showed similar maximum strains and no bursts. The one excepted test did not burst, but it was also found to only have undergone $2.2 \%$ hoop strain. It was noted that this test was the slower strain rate test, which would be expected to be more ductile than the high strain rate counterpart. For three out of six MBT tests, the maximum strain induced on the cladding specimen was in the plane strain state. For two of the remaining tests, the maximum strains occurred at negative axial strains, with one of them being closer to a uniaxial test. The remaining test was closer to the uniaxial loading path, but it was the slow strain rate test.

- The CrZr4 material's coating cracked around the circumference of the MBT specimen, likely due to the compression where the "corner" of the ballooning occurred. More testing is recommended with a higher quality coating to ensure that this behavior does not persist. The Zry-4 cladding itself did not burst, so this coating behavior is not expected to affect PCMI performance, but considering the small strains required to produce the cracks, it should be investigated.

- Zry-4 surface roughness was found to significantly impact coating uniformity and adherence. The coating was produced on nuclear service-spec Zry- 4 with $\mathrm{Ra} \leq 0.36$, where surface defects as large as 4.9 microns were found. The coated materials showed cracks and divots in the AR condition, which was expected to be from the surface roughness and coating process parameters. SATS and MBT tests showed that the cracked coating did not negatively impact the cladding behavior, but it also provided no benefit. Importantly, with this finding, it was concluded that no extra design-basis LOCA or PCMI-phase RIA performance issues arise from cladding defects. The coating cracks discovered at the edge of the MBT gauge section should be investigated, but they did not appear to negatively impact the cladding. 


\section{REFERENCES}

[1] K. Terrani, "Accident tolerant Fuel Cladding Development: Promise, Status, and Challenges," Journal of Nuclear Materials, no. 501, pp. 13-30, 2018.

[2] S. Zinkle, K. Terrani, J. Gehin, L. Ott and L. Snead, "Accident tolerant Fuels for LWRs: A Perspective," Journal of Nuclear Materials, no. 448, pp. 374-379, 2014.

[3] T. Alam, M. Khan, M. Pathak, K. Ravi, R. Singh and S. Gupta, "A Review on the Clad Failure Studies," Nuclear Engineering and Design, no. 241, pp. 3658-3677, 2011.

[4] N. Capps, Y. Yan, A. Raftery, Z. Burns, T. Smith, K. Terrani, K. Yueh, M. Bales and K. Linton, "Integral LOCA Fragmentation Test on High-Burnup Fuel," Nuclear Engineering and Design, vol. 367, p. 110811, 2020.

[5] M. Cinbiz, N. Brown, R. Lowden, K. Linton and K. Terrani, "RIA Simulation Tests Using Driver Tube for ATF Cladding," Oak Ridge National Laboratory, Oak Ridge, 2017.

[6] Y. Yamamoto, B. Pint, K. Terrani, K. Field, Y. Yang and L. Snead, "Development and Property Evaluation of Nuclear Grade Wrought FeCrAl Fuel Cladding for Light Water Reactors," Journal of Nuclear Materials, no. 467, pp. 703-716, 2015.

[7] Y. Yamamoto, K. Kane, B. Pint, A. Trofimov and H. Wang, "Report on Exploration of New FeCrAl Heat Variants with Improved Properties," Oak Ridge National Laboratory, Oak Ridge, TN, 2019.

[8] B. Garrison, P. Champlin, M. Howell, M. Cinbiz, M. Gussev, C. Petrie and K. Linton, "Progress Report on Length Dependence of Severe Accident Test Station Integral Testing," Oak Ridge National Laboratory, Oak Ridge, TN, 2020.

[9] C. Massey, K. Terrani, S. Dryepondt and B. Pint, "Cladding Burst Behavior of Fe-Based Alloys under LOCA," Journal of Nuclear Materials, vol. 470, pp. 128-138, 2020.

[10] N. Brown, B. E. Garrison, R. Lowden, M. Cinbiz and K. Linton, "Mechanical Failure of Fresh Nuclear Grade Iron-Chromium-Aluminum $(\mathrm{FeCrAl})$ Cladding under Simulated Hot Zero Power Reactivity Initiated Accident Conditions," Journal of Nuclear Materials, no. 539, p. 152352, 2020.

[11] M. Cinbiz, N. Brown, R. Lowden, M. Gussev, K. Linton and K. Terrani, "Report on Design and Failure Limits of SiC/SiC and FeCrAl ATF Cladding Concepts under RIA," Oak Ridge National Laboratory, Oak Ridge, TN, 2018.

[12] P. Rudling and L. Jernkvist, "Nuclear Fuel Behavior under RIA Conditions," Advanced Nuclear Technology International, Mölnlycke, Sweden, 2016.

[13] J. Desquines, D. Koss, A. Motta, B. Cazalis and M. Petit, "The Issue of Stress State during Mechanical Tests to Assess Cladding Performance during a Reactivity Insertion Accident (RIA)," Journal of Nuclear Materials, vol. 412, pp. 250-267, 2011.

[14] Y. Bai and T. Wierzbicki, "A new Model of Metal Plasticity and Fracture with Pressure and Load Dependence," International Journal of Plasticity, vol. 24, pp. 1071-1096, 2008.

[15] J. Desquines, D. Koss, A. Motta, B. Cazalis and M. Petit, "The Issue of Stress State During Mechanical tests to Assess Cladding Performance during a Reactivity-Initiated Accident," Journal of Nuclear Materials, vol. 412, pp. 250-267, 2011. 
[16] K. Yueh, J. Karlsson, J. Stjärnsäter, D. Schrire, G. Ledergerber, C. Munoz-Reja and L. Hallstadius, "Fuel Cladding Behavior under Rapid Loading Conditions," Journal of Nuclear Materials, no. 469, pp. 177-186, 2016.

[17] M. Cinbiz, M. Gussev, K. Linton and K. Terrani, "An Advanced Experimental Design for Modified Burst Testing of Nuclear Fuel Cladding Materials during Transient Loading," Ann. Nucl. Energy, vol. 127, pp. 30-38, 2019.

[18] K. Yueh, "Applicability of Modified Burst Test Data to Reactivity Initiated Accident," Journal of Nuclear Materials, vol. 488, pp. 338-345, 2017.

[19] J. Blaber, B. Adair and A. Antoniou, "Ncorr: Open-Source 2D DIGITAL IMAGE CORRELATION Matlab Software," Experimental Mechanics, vol. 55, pp. 1105-1122, 2015.

[20] C. Withmarsh, "Review of Zircaloy-2 and Zircaloy-4 Properties Relevant to N.S. Savannah Reactor Design," Oak Ridge National Laboratory, Oak Ridge, TN, 1962.

[21] ASTM International, "Standard Specification for Wrought Zirconium and Zirconium Alloy Seamless and Welded tubes for Nuclear Service (Except Nuclear Fuel Cladding)," ASTM International, West Conshohocken, PA, 2017.

[22] A. Velente-Feliciano, "HiPIMS: a New Generation of Film Deposition Techniques for SRF Applications," in SRF 2013, Paris, France, 2013.

[23] C. Kuo, C. Lin, Y. Lin and J. Chang, "Effects of Cathode Voltage Pulse Width in High Power Impulse Magnetron Sputtering on the Deposited Chromium Thin Films," Coatings, vol. 10, no. 6, pp. 1-11, 2020.

[24] A. de Monteynard, F. Schuster, A. Billard and F. Sanchette, "Properties of Chromium Thin Films Deposited in a Hollow Cathode Magnetron Powered by Pulsed DC or HiPIMS," Surface Coatings Technology, vol. 330, pp. 241-248, 2017.

[25] R. Chapman, "Multirod Burst Test Program Progress Report," Oak Ridge National Laboratory, Oak Ridge, 1978.

[26] D. Powers and R. Meyer, "Cladding Swelling and Rupture Models for LOCA Analysis," Nuclear Regulatory Commission, 1980.

[27] B. Pint, K. Terrani, M. Brady, T. Cheng and J. Keiser, "High Temperature oxidation of Fuel Cladding Candidate Materials in Steam-Hydrogen Environments," Journal of Nuclear Materials, vol. 440, pp. 420-427, 2013.

[28] T. Feng, J. Wang, Y. Zhou, P. Song, M. Wang, R. Dailey, W. Tian and M. Corradini, "Quantification of the Effect of Cr-Coated-Zircaloy Cladding during a Short Term Station Black Out," Nuclear Engineering and Design, vol. 363, p. 110678, 2020.

[29] K. Kane, P. Stack, P. Mouche, R. Pillai and B. Pint, "Steam Oxidation of Chromium Corrosion Barrier Coatings for SiC-Based Accident Tolerant Fuel Cladding," Journal of nuclear materials, vol. 543, p. 152561, 2021.

[30] Y. Yan, B. Garrison, M. Howell and G. Bell, "High-Temperature Oxidation Kinetics of SpongeBased E110 Cladding Alloy," Journal of Nuclear Materials, vol. 499, pp. 595-612, 2017.

[31] J. Cathcart, R. Pawel, R. McKee, R. Druschel, G. Yurek, J. Campbell and S. Jury, "Zirconium Metal-Water Oxidation Kinetics IV. Reaction Rate Studies," Oak Ridge National Laboratory, Oak Ridge, TN, 1977. 